\title{
André Lorulot
}

[]André Georges Roulot, dit Lorulot

(1932)

\section{L'ÉGLISE}

ET LA GUERRE

Un document produit en version numérique par Claude Ovtcharenko, bénévole, Journaliste à la retraite près de Bordeaux, à $40 \mathrm{~km}$ de Périgueux

Courriel: c.ovt@wanadoo.fr

Dans le cadre de la collection: "Les classiques des sciences sociales"

Site web: http://classiques.uqac.ca/

Une collection développée en collaboration avec la Bibliothèque

Paul-Émile-Boulet de l'Université du Québec à Chicoutimi

Site web: http://bibliotheque.uqac.ca/ 
Cette édition électronique a été réalisée par Claude Ovtcharenko, bénévole, journaliste à la retraite près de Bordeaux, à $40 \mathrm{~km}$ de Périgueux.

Courriel: c.ovt@wanadoo.fr

à partir de :

ANDRÉ LORULOT, L'ÉGLISE ET LA GUERRE. Paris : Les Éditions L'idée libre, 1932. Collection : La Bibliothèque du Libre Penseur.

[De la guerre de 1914-1918]

Polices de caractères utilisée :

Pour le texte: Times New Roman, 14 points.

Pour les citations : Times New Roman 12 points.

Pour les notes de bas de page : Times New Roman, 12 points.

Édition électronique réalisée avec le traitement de textes Microsoft Word 2004 pour Macintosh.

Mise en page sur papier format : LETTRE (US letter), 8.5'’ x 11'’)

Édition numérique réalisée le 20 mai 2006 à Chicoutimi, Ville de Saguenay, province de Québec, Canada.

\section{CFait avec}




\section{Table des matières}

Préface, par Henri Barbusse

Une lettre inédite du Général Percin à André Lorulot, 29 janvier 1920

Avertissement des éditeurs

Introduction, par Victor Margueritte

I. $\quad$ Causes lointaines

II. Responsabilités de la guerre de 1870

III. Les cléricaux pendant l'avant-guerre

IV. $\quad$ Pourquoi l'église désirait-elle la guerre ?

V. $\quad$ Culpabilité de l'Autriche

VI. Qu'a fait pie x pour modérer l'Autriche ?

VII. Le Vatican a poussé à la guerre

VIII. Hypocrisie de la prétendue neutralité papale

IX. Le rôle de la Russie

X. $\quad$ Poincaré et son action personnelle

XI. L'assassinat de Jaurès

XII. La falsification du catéchisme

XIII. «La guerre est divine "

XIV. L'église est-elle devenue pacifiste?

XV. Un plaidoyer maladroit

XVI. Le problème de population et l'Église

XVII. Leur "patriotisme"

XVIII. Qui fera la paix?

Appendice. Une page d'histoire 


\section{André Georges Roulot, dit Lorulot}

L'Église et la guerre

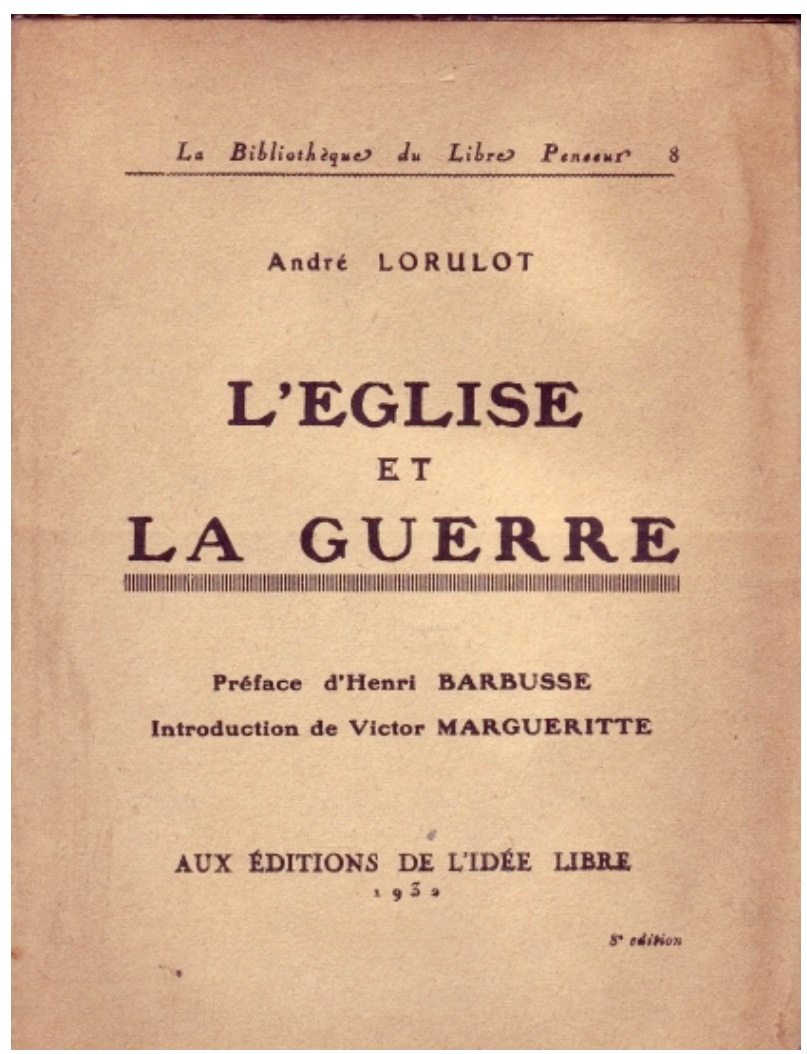

Paris : Éditions L’idée libre, 1932. Collection : La Bibliothèque du Libre penseur. 
André Lorulot, L’Église et la guerre (1932)

\section{Préface}

\section{Par Henri Barbusse}

André LORULOT est un militant anticlérical convaincu et ardent qui a rudement payé de sa personne depuis un quart de siècle. À l'âge de vingt ans, il avait déjà été condamné en Cour d'assises pour propagande contre le bellicisme (l'Église et la Guerre s'entendent comme deux amantes). Après ses emprisonnements de 1907-1908, il en subit un autre pendant les quatre années de guerre. Cela nous prouve qu'à ce moment il disait nettement des choses justes. Dès l'armistice, dès la paix, qui, on le sait bien, n'est qu'une armistice maquillée et précaire, il a repris sur tout le territoire, dans des centaines de réunions publiques, devant des milliers et des milliers d'auditeurs toujours renouvelés, la propagande contre la guerre et contre le cléricalisme, contre le couple du soudard et du prêtre, ayant parfois à faire de véhémentes contradictions de la part d'astucieux avocats de la mauvaise cause depuis le chanoine Desgrange et l'abbé Viollet, jusqu'à MM. Ernest JUDET et Marc SANGNIER.

Spécialisé dans la lutte contre le pouvoir sinistre et obscur de l'Église qui pèse aujourd'hui d'un poids si lourd sur les destinées des multitudes humaines, par son organisation formidable, ses accointances de plus en plus cyniquement étalées avec les gouvernements, sa 
main mise restée sur l'éducation malgré toutes les lois bourgeoises LORULOT a été amené à se documenter de plus en plus profondément sur ce tragique problème.

De nos jours, la sincérité active est rare ; mais la sincérité documentée et, si l'on peut dire, positive, l'est infiniment plus. C'est pourtant la seule qui soit armée valablement, et qui, en définitive, serve à quelque chose. Tous les honnêtes gens, tous ceux dont la mentalité n'a pas été estropiée par des instituteurs ou des professeurs plus ou moins ensoutanés ou par des parents intoxiqués par la "piété »se révoltent devant les contradictions grossières et les manœuvres perpétrées par l'Église, dans des buts de domination et surtout de profit à l'encontre des commandements les plus stricts de la religion. Mais à mesure que la colère, de fait en fait, s'instruit, qu'elle se base sur la critique exacte et méthodique des faits, on aperçoit tous les liens qui font de l'innombrable personnel de la religion, depuis le petit curé d'apparence bonasse qui se réclame de la bonté de Dieu (comme la chauve-souris de la fable qui dit : Je suis oiseau, voyez mes ailes) jusqu'aux cardinaux et au pape, les agents d'un immense service d'asservissement des masses. Et c'est ainsi que se précise dans les volontés flottantes la nécessité de crier : Non!

Sans doute, le matérialisme, l'esprit scientifique positif, qui est en contradiction criante avec les mirages d'un dogme, ont bien été utilisés par la bourgeoisie en vue de son intérêt de classe dans la lutte qu'elle a naguère entreprise contre les privilèges de l'aristocratie et du clergé et aussi contre certaines vagues de réaction monarchique. Mais, aujourd'hui, ne nous laissons plus prendre à ce piège. La grande force d'en bas, le prolétariat universel, tend à son émancipation. Devant ce danger qui la menace, la bourgeoisie se saisit de la croix qui est une de ses armes «spirituelles et morales », si on peut dire, contre le peuple. L'Église et la bourgeoisie ont maintenant partie liée dans tous les pays du monde sauf un : l'État Ouvrier et Paysan de l'Est.

Les querelles du fascisme et du pape (réintégré dans ses vieilles prérogatives par le fascisme) n'infirment nullement cette collusion internationale, car elles portent sur une question de direction, ou plutôt de dirigeants, non sur une question de principes. Que tous ces conflits 
passagers ne nous donnent pas le change, pas plus que la légende du libéralisme bourgeois.

C'est pourquoi nous devons accueillir avec un grand intérêt tout ouvrage qui, comme celui-ci, parvient, en rassemblant un nombre imposant de preuves, à ouvrir les yeux du peuple — et des intellectuels non entraînés par leur classe - sur les dessous des intrigues religieuses qui se sont manifestées à un moment donné. Il s'agit dans un riche réquisitoire d'André LORULOT de ce qui s'est passé dans ces sphères avant et pendant la guerre de 1914, série innombrable de tractations dominées par les fluctuations honteuses du pape (non pas devant l'interprétation chrétienne des événements, dont il se soucie aussi peu que le premier homme sensé venu, mais en présence de ses intérêts temporels).

La religions, basée sur l'exploitation d'instinctives aspirations individuelles du cœur humain et principalement la peur de la mort, est devenue une toute puissante institution appuyée par la force d'État, ayant pour but de changer les foules en troupeaux domestiqués, taillables, corvéables, épuisables et tuables à merci. Si l'état d'esprit moderne l'oblige à recourir à des moyens plus industrieux, plus diplomatiques, plus perfectionnés que jadis, la fondation de Saint-Paul n'en poursuit pas moins imperturbablement le même objectif éternel.

Et voilà que son sort et son action, on ne saurait trop le répéter, sont indissolublement attachés à ceux de la bourgeoisie capitaliste, impérialiste et esclavagiste acculée aujourd'hui dans des crises définitives par le déséquilibre de ses méthodes d'exploitation générale, et qui, autant que l'Église, et à tout aussi juste titre, a peur du peuple comme du Déluge.

Pour tous ceux aux yeux desquels la légende propagée par la grande presse touchant les causes de la grande guerre n'est qu'hypocrisie et mensonge, nonobstant l'estampille de l'article $231 \mathrm{du}$ traité de Versailles, et qui ont fini par comprendre que la seule responsabilité incombe à un régime social et à tous ses suppôts variés, un grand profit se dégagera de tout ce que l'étude ci-après comporte de documentation objective et positive sur les derniers faits et gestes de la grande persécuteuse catholique et romaine. Pour les autres, cela se- 
ra une révélation salutaire. De toute façon, la divulgation de faits réels ne peut qu'aider, sur toute la ligne, le prolétariat international à reconnaître ses vrais ennemis et à déblayer sa vraie voie révolutionnaire.

\section{Henri BARBUSSE}


André Lorulot, L'Église et la guerre (1932)

\title{
Une lettre inédite du Général Percin à André Lorulot
}

\author{
29 janvier 1920
}

$\underline{\text { Retour à la table des matières }}$

Cher citoyen Lorulot,

Je crois être le premier militaire qui ose dire que la guerre est un moyen stupide de régler les différends qui peuvent s'élever entre les peuples. Plus stupide encore que le duel entre particuliers. Dans le duel, en effet, l'adresse et la bravoure jouent encore un certain rôle. À la guerre, au contraire, c'est souvent le plus bête et le moins brave qui réussit. Le hasard a une influence prépondérante.

Cela n'empêche pas qu'on puisse, par un certain savoir-faire, mettre la chance de son côté. C'est ce que n'ont pas su faire les préparateurs de la guerre de 1914-1918.

Dans «Lille » et dans «1914 ", je fais ressortir leur insuffisance. Je dis que JOFFRE, l'incapable, est plus à plaindre qu'à blâmer. On l'a pris presque malgré lui. On l'a choisi, non pas malgré son incompétence, mais en raison même de cette incompétence, qui devait assu- 
rer la suprématie du général de Castelnau. Ce fut le crime de MESSI$M Y$ et du général $P A U$.

Ce fut le crime du général BUAT, un des préparateurs du «Plan 17 », que, pour le récompenser de son exploit, on vient de nommer chef d'État-Major de l'armée - où il nous prépare la loi de deux ans.

Veuillez agréer, etc...

\section{Général PERCIN}

Je reproduis cette lettre du général Percin (datée du 29 janvier 1920). On y aperçoit clairement la machination cléricale contre la Paix et contre la République. L'importante correspondance que j'ai échangée avec le courageux "général républicain » serait à publier toute entière. Je recommande vivement la lecture de ses livres, ainsi que celle des ouvrages de Victor MARGUERITTE: Au bord du gouffre et Les Criminels.
A. L. 
André Lorulot, L'Église et la guerre (1932)

\section{Avertissement des éditeurs}

$\underline{\text { Retour à la table des matières }}$

L'auteur du présent ouvrage est un militant convaincu de l'Antimilitarisme et de l'Anticléricalisme. Il est sur la brèche depuis vingt-cinq années déjà et il s'est efforcé, par la parole et par la plume, d'ouvrir les yeux à ses concitoyens.

Besogne ingrate et difficile!

Le sujet du présent ouvrage a été développé par André LORULOT, dans des centaines de réunions publiques, devant des dizaines de réunions publiques, devant des dizaines de milliers d'auditeurs appartenant aux classes et aux milieux les plus différents, en controverse avec des adversaires parfois éminents.

Le moment nous paraît bien choisi pour publier un livre de ce genre, dont l'équivalent n'a encore jamais été publié à ce jour.

Tout le monde se dit pacifiste, mais bien peu d'hommes ont pris la peine d'étudier les conditions dans lesquelles se produisent les guerres. Ne voit-on pas des naïfs s'associer, pour la Paix, avec des réactionnaires et des cléricaux, rêver d'un "Cartel 》 dans lequel entreraient des Jésuites et des Libres Penseurs, des défenseurs du régime capitaliste et des révolutionnaires, des réactionnaires et des démocra- 
tes. Quelle comédie - et quel danger, si les hommes de gauche tombaient dans le piège qui leur est tendu par l'Église, cet éternel ennemi de la Paix!

LORULOT n'est pas de ceux qui tergiversent ou qui fardent leur pensée.

Il parle en toute conscience et nous souhaitons qu'il soit entendu, dans l'intérêt même de l'humanité.

\author{
LES ÉDITIONS DE L’IDÉE LIBRE
}


En 1917, LORULOT avait publié, malgré la Censure, un important ouvrage intitulé : Barbarie Allemande... et Barbarie Universelle (Le livre Rouge des Atrocités Mondiales), avec préface du célèbre et regretté professeur Auguste FOREL. Lire le chapitre très élogieux consacré au livre de LORULOT par le général PERCIN (dans Guerre à la Guerre). Cette publication valut évidemment à LORULOT des animosités et des tracasseries. 
André Lorulot, L’Église et la guerre (1932)

\title{
Introduction
}

\author{
Par Victor Margueritte
}

$\underline{\text { Retour à la table des matières }}$

Mon cher André Lorulot,

Vous m'avez, au moment où vous citiez devant la justice les éternels « Tartuffe » que l'Idée Libre effarouche à moins qu'elle ne les mette en furie, fait l'honneur de souhaiter mon témoignage.

On vous avait traité de pornographe, parce que vous n'avez pas craint, dans votre longue lutte contre le mensonge et l'hypocrisie, de démasquer les turpitudes dont ces Messieurs sont coutumiers, sous la robe ou le manteau.

Vous avez bien fait, alors de confondre les calomniateurs ! pauvres gens qui à se voir nus au miroir de la vérité extériorisent, en accusant le voisin, le bas-fond même de leurs âmes crapuleuses. Je n'ai pour ma part jamais répondu à leurs injures que par le mépris, philosophie qui est de mon âge, et que je conçois que vous n'ayiez pas eue. Vous leur fites ainsi, au demeurant, bien de l'honneur...

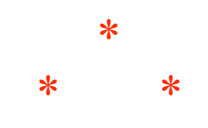


Aujourd'hui, venant de flétrir, dans un vigoureux petit livre, ces antiques sœurs du mal, l'Église et la guerre, vous me demandez de présenter au public votre essai.

C'est un soin superflu. Le généreux et hardi sociologue que vous êtes n'a qu'à paraître, chacun sait qu'André LORULOT est synonyme de franchise, de clairvoyance et de courage.

Toutes ces qualités n'étaient point de trop pour dénoncer, à l'heure même où l'Église se range du côté de la paix, les liens millénaires qui l'ont si souvent rattachée à la guerre, et qui, durant la dernière grande tuerie, nous ont montré toutes les chapelles nationales asservies aux féroces dieux des patries, alors que la Pape prêchait seul, dans le désert sanglant, son hymne rituel à la fraternité humaine et à la miséricorde divine.

Que penser, aujourd'hui, de ces adjurations lancées du haut de la chaire de Saint-Pierre, de ces appels à la concorde et à l'union?

Invinciblement, au souvenir instructif des siècles, l'historien revoit la longue horreur des guerres religieuses, avec son cortège d'Inquisitions, de Saint-Barthélemy, de défenestrations, soit que le catholicisme milite pour sa propre suprématie, soit qu'il se ravale au service des puissants contre les humbles, des exploiteurs contre les exploités, il fut et il reste son instrument de règne politique, un régime d'intolérance et d'oppression. L'Église, avec son mirage de Paradis et son cauchemar d'Enfer, n'est qu'un trompe-l'œil pour esprits simples. Attrape-nigauds juste bon à capter des vieilles filles et des peuples enfants !

Est-ce à dire qu'il n'y ait point parmi les vicaires du Christ qu'ils siègent au trône de Saint Pierre ou dans quelque pauvre cure de campagne - de nobles esprits et de braves cœurs ? J'en connais pour ma part, mais ils sont l'exception et le haut Clergé les tient pour serviteurs suspects.

Aussi est-on fondé à penser que lorsque le souverain de la Cité du Vatican - est-ce le Pape Blanc ou le Pape Noir? — recommande à 
ses prêtres la litanie pacifique, c'est qu'il pense sans doute que la pêche aux âmes doit être aujourd'hui plus fructueuse aux eaux troubles de la paix, qu'elle ne l'a été (et ne le serait) aux eaux sanglantes de la guerre...

Quoiqu'il en soit, je pense que votre livre, mon cher LORULOT, constitue un enseignement salutaire, en même temps qu'un acte sans nul doute courageux. Puisse-t-il convaincre vos lecteurs qu'il n'y a sur terre qu'un seul Dieu, celui que chacun porte en soi, s'il est le moins du monde animé par le véritable « Saint-Esprit». Je veux dire le sentiment de la justice et le sens de la solidarité.

\section{Victor MARGUERITTE.}


« Le sang versé lave les péchés. »

Exode (XXIX. 20/21).

« Les fléaux, comme la peste et la guerre, sont nécessaires pour réveiller la foi et épurer les mœurs. Et qui oserait dire, à notre époque d'impiété et de sensualisme raffiné, qu'ils ne sont pas mérités ? Mais ce sont aussi des instruments de miséricorde... Les ossements de nos champs de bataille seront des ossements glorifiés ; les âmes de ceux qui ont été fauchés par les épidémies ou les obus jouissent de la gloire éternelle qu'elles n'auraient jamais possédée sans ces terribles épreuves qui les ont rappelées à la réalité immortelle et réunies à Dieu. »

(L’Ami du Clergé, 23-4-25.)

« Ils ont provoqué une guerre injuste, c'est un crime dont ils seront châtiés icibas et plus tard. »

$$
\begin{aligned}
& \text { Chanoine Gaudeau, } \\
& \text { (à Saint Augustin, Paris). }
\end{aligned}
$$

« Dieu a été, il est avec nos héroïques soldats, à l'est et à l'ouest, sur mer et dans l'air. Il a été, et il est avec notre peuple allemand qu'embrase la détermination de tenir jusqu'au bout et la confiance dans la victoire finale. C'est avec Dieu que nos soldats sont partis pour cette guerre. »

\section{Cardinal HARTMANN, (Archevêque catholique de Cologne).}

« Nous ne lâcherons l'Allemagne que lorsqu'elle aura mis haut les mains, sans armes. »

Abbé SeRTILlanges,

(à la Madeleine, Paris 27 septembre 1915).

«Si Poincaré était battu (à l'Élysée), ce serait pour nous une catastrophe. »

ISVOLSKY. 


\section{I \\ CAUSES LOINTAINES}

À la mémoire de mes bons amis, de mes vaillant frères de combat contre le Cléricalisme et la Guerre, Léon PROUVOST et Émile HUREAU, avec mes regrets les plus affectueux.

A. L.

$\underline{\text { Retour à la table des matières }}$

Depuis 1914, les efforts les plus persévérants ont été faits, dans tous les pays, pour élucider les véritables causes de la Guerre.

D'innombrables volumes ont été publiés, dont les conclusions sont souvent divergentes.

Bornons-nous à constater, très impartialement, que le problème est complexe et que les responsabilités sont nombreuses et variées.

Seuls des esprits simplistes peuvent encore croire que les responsabilités incombent à un seul pays, ou à une seule personne. 
Les causes sont nombreuses et les responsabilités peuvent être équitablement partagées entre tous les gouvernements belligérants.

(Russie, Allemagne, France, Autriche, Serbie, Angleterre, etc., ont leur part respective de culpabilité. Les rivalités commerciales, les appétits des gros métallurgistes, les haines nationales - panslavisme, pangermanisme - le désir de certains gouvernements de trouver dans la guerre un dérivatif aux revendications populaires, tout cela a joué un rôle dans la genèse de l'abominable conflit.)

Quelle est la part de l'Église dans ces responsabilités ?

Un certain nombre d'auteurs ont compris qu'elle n'était pas innocente, qu'elle avait dû manœuvrer sournoisement pour rendre la guerre inévitable. Cependant, ce rôle n'a pas été mis en lumière d'une façon suffisante et nous voulons essayer, par ce modeste travail, de rassembler les arguments essentiels qui permettent d'accuser l'Église d'une façon sérieuse.

Pour saisir le jeu de l'Église, une grande clairvoyance est nécessaire, précisément parce que ce jeu est caché et sournois.

Les Jésuites sont passés maîtres, non seulement dans l'art de commettre des crimes, mais dans l'art plus subtil d'effacer jusqu'à la moindre trace les preuves de leur participation dans l'organisation de ces crimes. Lorsque l'attentat est accompli, ils ne manqueront jamais de protester vertueusement, de proclamer leur bonne foi et leur innocence.

Ce système leur a souvent réussi, ce qui rend assez pénible la découverte de la vérité. Néanmoins, en utilisant certaines erreurs de tactique et certaines imprudences, certains documents irréfutés, en interrogeant l'histoire, en analysant l'attitude de la plupart des chefs du clergé catholique, nous pouvons aboutir sans craindre d'être sérieusement contredit, à cette conclusion que l'Église peut être considérée comme l'un des principaux responsables de la Guerre de 1914. C'est ce que nous allons démontrer. 
Chacun sait qu'il existe une solidarité historique puissante entre les événements présents et ceux qui les ont précédés.

Dans la société humaine, comme dans la nature, il n'y a pas de hasard, ni de miracle. Tout est déterminé. Tout effet nécessite une cause, qui l'a produit. Et l'effet produit engendrera à son tour des conséquences nouvelles.

Or, la guerre de 1914 a été précisément le fruit de la politique européenne, des agissements politiques qui se seront déroulés, particulièrement au cours des cinquante années qui l'ont précédée.

Certains diront: La France a été entrainée dans la guerre par la Russie.

D'autres constateront: jamais la France n'aurait marché contre l'Allemagne si elle avait pu obtenir, pacifiquement, le retour de l'Alsace et de la Lorraine.

La guerre de 1914 est le prolongement de la guerre de 1870, comme la funeste alliance franco-russe.

Je ne veux pas remonter plus haut dans l'Histoire. Et pourtant, il y aurait beaucoup à dire... Les guerres napoléoniennes ont aliéné à la France les sympathies de l'Europe, c'est un fait. Mais ces guerres n'étaient-elles pas une réaction contre la politique cléricale et monarchique, qui visait à encercler la France révolutionnaire et à abattre brutalement la déclaration des droits de l'Homme et du Citoyen ? Cette déclaration ne fut-elle pas condamnée solennellement par le Pape ? Le même pape ne fut-il pas l'instigateur des guerres de Vendée — et du régime terroriste qui devint par la suite indispensable.

Plus tard, le Clergé se prosterne aux pieds de Napoléon ${ }^{1}$.

1 «Dès le commencement de 1805, il avait été fait des mandements dans chaque métropole pour justifier cette nouvelle guerre et encourager les conscrits à marcher promptement. Les évêques recommencèrent à nouveau, et ils épuisèrent les citations de l'Écriture pour démontrer que l'Empereur était protégé 
En 1815, lorsque Napoléon succomba, les cléricaux et les royalistes accueillirent à bras ouverts l'envahisseur étranger. L'écrasement de la France voltairienne fut considéré par l'Église comme un triomphe!

Retenons cet état d'esprit, que nous aurons l'occasion de retrouver souvent et revenons à la guerre de 1870 .

Il nous suffira du reste d'un examen rapide pour nous convaincre que cette guerre fut considérablement influencée par l'Église.

par le Dieu des armées... Quand il exigea la levée des conscrits de 1808, il ordonna, selon la coutume, aux évêques d'exhorter les paysans à se soumettre. » - (Mme de REMUZAT (confidente de l'Impératrice JoséPHINE), citée par G. DUPIN. 


\section{II \\ RESPONSABILITÉS DE LA GUERRE DE 1870}

Il est devenu presque banal de le dire : la guerre avec la Prusse pouvait très bien être évitée, car il n'y avait alors aucun litige grave entre les deux pays. Mais il y avait à la Cour Impériale un « parti de la guerre », constitué surtout par les grands officiers (les militaires ne peuvent évidemment pas être pacifistes, à part de très rares exceptions) qui rêvaient de galons et de prouesses glorieuses - accomplies par leurs troupes.

Le chef de ce parti était l'Impératrice.

Dans ses Souvenirs, récemment publiés, notre regretté ami le général PERCIN a écrit : "L'Empereur était impassible. Il regardait droit devant lui, d'un air fatigué et ennuyé. On avait l'impression que ce n'était plus lui qui régnait sur la France. Et, dans le public, dans l'armée surtout, la politique belliciste de l'Impératrice avait plus de partisans que la sienne. On ne criait pas encore : « À Berlin!», mais un vent d'animosité contre la Prusse, un vent de guerre, soufflaient déjà sur le pays. " 
Plus loin, le général PERCIN (témoin oculaire, ne l'oublions pas) écrit :

«J'ai su plus tard, par un livre de Pierre de LANO, intitulé L'Impératrice Eugénie, livre édité en 1891, par la Maison HAVARD, que, lorsque le Conseil des Ministres présenta à l'Empereur le décret relatif à l'ouverture des hostilités, ce dernier refusa d'abord de le signer. Comme le conseil insistait, il se mit en colère et déchira le papier. Puis, il se retira dans sa chambre, où, épuisé par la lutte qu'il venait de soutenir, il se coucha. Prise de colère à son tour, l'Impératrice fit rétablir par les ministres le libellé du papier et elle força l'empereur à le signer. »

Nous pourrions multiplier de telles citations, empruntées à une foule d'auteurs. il est certain (sans vouloir diminuer les torts qui incombent à BISMARCK) que l'Impératrice a voulu la guerre ${ }^{2}$.

N'avons-nous pas le droit de supposer que l'attitude belliciste de l'Impératrice lui était conseillée ou indiquée par son entourage clérical ? Ou par ses confesseurs, qui dirigeaient à leur gré la superstitieuse

2 Un aveu de La Croix (article de Louis CADARS, 1-3-31) : "Cependant, dans son NAPOLÉON III, M. AUBRY s'est montré quelque peu sévère pour l'Impératrice. Sans doute l'influence qu'elle exerça sur la politique générale du pays ne fut pas toujours heureuse. Mais il n'est pas prouvé que cette influence ait été après tout plus néfaste que celle des ordinaires conseillers de NAPOLÉON III. Ce que l'on a appelé « la politique blanche » de l'Impératrice comportait assurément des desseins plus fermes partant plus bienfaisants que les utopies pacifistes et sanguinaires du pauvre Empereur...»

Les « utopies pacifistes » (et sanguinaires ?) de NAPOLÉON III ?

On ne saurait mieux avouer qu'il ne voulait pas la guerre et qu'on s'est servi de l'Impératrice pour la lui imposer.

La chose était d'autant plus facile que l'Empereur, faible de volonté, avait toujours ménagé le parti clérical.

$\mathrm{Au}$ lendemain même du Coup d'État, BADINGUET s'était appuyé sur l'Église, non par conviction mais par intérêt :

« Au lendemain du 2 décembre 1851, le Prince-Président comprit très bien que son règne aurait la vie courte s'il ne s'appuyait sur la droite catholique. Sans hésiter, il poussa de ce côté-là. La loi FALLOuX à l'intérieur et l'expédition de Syrie à l'extérieur témoignèrent $\mathrm{d}$ son désir d'être agréable à ceux que l'on appelait les ultramontains... » - (A. DARGOIRE, La Croix, 118-31.) 
espagnole, qui s'écriait joyeusement : «J'ai ma guerre ! », lorsque le conflit éclata ${ }^{3}$.

En tout cas, le moins qu'on puisse dire, c'est que l'Église n'a rien fait — bien au contraire - pour calmer la guerrière Eugénie !

En réalité, le Vatican avait besoin de la guerre de 1870, pour rétablir sa situation bien compromise. Si l'Empire français avait triomphé, comme on l'espérait à tort, le Vatican pouvait escompter de sa part un appui des plus efficaces.

D'autre part, le Concile du Vatican (1870) était fortement divisé sur la question de l'infaillibilité du Pape. Beaucoup d'évêques résistaient aux prétentions de la Papauté. C'est à ce moment précis que la guerre se produisit, mettant fin aux controverses et permettant d'obtenir le vote de l'Infaillibilité, dans la précipitation et le désarroi de la fin du Concile, obligé de se disperser.

Lorsque la France eut été vaincue, les exigences de la Prusse auraient pu être tenues en échec, si le gouvernement français avait été soutenu par ceux des autres pays. Malheureusement, ils se détournèrent tous de nous, à commencer par l'Italie qui ne pardonnait pas à NAPOLÉON III d'avoir envoyé des troupes à Rome au secours du pape, dont les Italiens avaient fini par secouer la tyrannie.

Le Prince JÉRÔME (propre neveu de NAPOLÉON I ${ }^{\mathrm{er}}$ et cousin de NAPOLÉON III), analysant les causes de la guerre de 1870, écrit : «Une grande leçon ressort de ces faits, c'est que le parti clérical a été assez fort pour dominer l'Empereur NAPOLÉON III. ") (Revue des Deux

3 Déjà, lors de la funeste expédition du Mexique (qui eut de fâcheuses répercussions sur les événements de 1870), l'Impératrice Eugénie avait exercé une déplorable influence, dans le sens de la guerre.

Le Président du Mexique, Juarez, avait des tendances anticléricales et l'on voulut le remplacer par un Empereur à la dévotion du clergé, l'Autrichien MAXIMILIEN.

Le vicomte de BEAUMONT-VASSY écrit dans son histoire intime du Second Empire (1874) : «D'après les renseignements les plus sûrs, l'expédition du Mexique est sortie toute décidée, toute faite, du petit salon de l'Impératrice. » Mgr LABASTIDE, archevêque de Mexico, avait tout manigancé. 
Mondes, 1-4-1878.) Voilà un témoignage difficile à récuser, il me semble...

Ces deux seuls faits : $1^{\circ} 1^{\prime}$ Impératrice dévote, instrument des curés, a voulu la guerre; $2^{\circ}$ la politique cléricale de l'Empire a facilité l'isolement et l'écrasement de la France, suffisent à démontrer que notre thèse n'est nullement fantaisiste et que nos revers de 1870 (traité de Francfort, annexion de 1'Alsace par l'Allemagne) ont lourdement pesé sur la politique de la III ${ }^{\mathrm{e}}$ République pendant quarante ans.

On ne peut rien comprendre à la guerre de 1914, si l'on n'étudie pas d'abord, du point de vue français, les préliminaires que nous venons de rappeler. 


\section{III \\ LES CLÉRICAUX PENDANT L'AVANT-GUERRE}

$\underline{\text { Retour à la table des matières }}$

Et après 1870 ?

Le chanoine DesGRANGes me disait un jour, en conférence publique : BISMARCK a favorisé les idées républicaines et anticléricales en France, pour affaiblir notre pays.

L'argument a été souvent donné. Il est loin de correspondre à la réalité ${ }^{4}$.

Pour comprendre le point de vue de BISMARCK, reportons-nous à la correspondance qu'il échangea avec le Prince Henckel de DonnesMARCK.

Une étude sur cette édifiante correspondance a paru dans le Temps des 30 septembre et 11 septembre 1901, elle a été republiée dans les Cahiers idéalistes français ( $\mathrm{n}^{\circ}$ du 6 juillet 1917). Nous en citerons le suivant passage tout à fait symptomatique :

4 On en dit autant de la politique coloniale française, favorisée par Bismarck, dans le but de détourner nos chauvins de la revanche... 
« La lettre s'étend assez longuement sur cette conception singulière, qu'il y aurait... tout à craindre pour la paix si la Monarchie succédait en France à la République. C'est ce que BISMARCK, par la plume de son fils, appelle « l'autre agent». Cet autre agent qu'il voit tout puissant au lendemain du changement de régime, c'est le cléricalisme, c'est le Vatican, c'est le Gésù. alors la France risquerait de devenir le soldat du Pape. Il est curieux de noter cette conception identique de la diplomatie bismarckienne et du radicalisme français. " Sous un régime clérical, dit en propres termes la lettre que nous citons, l'armée française n'est pas autre chose que le Soldat du pape, qui doit marcher sur son ordre où les Jésuites veulent la diriger. »

Elle se termine par une nouvelle assurance des sentiments très pacifiques du chancelier :

« Nous ne voulons pas et nous n'avons pas besoin d'une guerre avec la France ; nous croyons aussi qu'elle n'éclatera pas fatalement aussi longtemps que le pape n'en donnera pas l'ordre exprès. Mais si ce dernier entre en scène, il n'y aura pas à espérer une longue paix... » (Cité par GENOLD, L'Église et la Guerre)

Bismarck savait très bien que l'Église est le grand fauteur de brouilles internationales et de guerres. N'a-t-il pas mené, en Allemagne même, une lutte ardente contre elle?

Il savait très bien qu'une France cléricale constituerait le plus grand danger pour la paix de l'Europe. La contrepartie n'est-elle pas vraie ? Nos nationalistes eux-mêmes ne proclament-ils pas qu'une Allemagne hitlérienne rendrait la paix impossible, tandis que le rapprochement serait aisé avec une Allemagne sincèrement républicaine ? Qu'on le veuille ou non, le cléricalisme et la monarchie ont toujours vécu de la guerre - et celle-ci ne disparaîtra que par l'avènement de la démocratie véritable.

Pour faire contrepoids à l'impérialisme allemand, on imagina de s'allier à la Russie tsariste, rejetant les avances de Guillaume en vue d'un rapprochement amical.

L'alliance russe a-t-elle été voulue et préparée au Vatican? 
C'est un prêtre qui répond par l'affirmative : «L'alliance russe, fruit des relations de la France avec le Saint-Siège... » Abbé CHAPTAL, curé de N.-D. du Travail de Plaisance, à Paris (cité Mercure de France, 1-12-21) 5 .

Rome aurait donc voulu, 20 ans avant la guerre de 1914, empêcher le rapprochement franco-allemand et faire d'une pierre deux coups : $1^{\circ}$ préparer la guerre ; $2^{\circ}$ jeter Marianne dans les bras du pays le plus réactionnaire du monde et paralyser ainsi notre évolution démocratique. Ce n'était pas mal joué.

Les événements confirment cette hypothèse, en tout cas.

Nous voyons, avant la guerre, que les éléments catholiques étaient en France les plus belliqueux. Les BARRÈs et les DÉROULÈDE, cléricaux déclarés, ne parlaient que de revanche, glorifiant les beautés (?) de la guerre, injuriant les hommes de gauche et se gaussant de leurs illusions pacifistes. Les militants socialistes n'étaient-ils pas accusés, JAURĖS en tête, d'être payés par le Kaiser?

Avec le concours des Millerand, des Briand, des Poincaré et autres politiciens néfastes, l'Église eut tôt fait de saboter l'œuvre républicaine de Combes, Pelletan, André.

« Il avait fallu cinq ans au général André pour ramener le haut commandement au loyalisme républicain. Avec l'honnêteté naïve d'un polytechnicien consciencieux, il avait recueilli des informations

5 Confirmation de cette thèse est fournie par un récent article du Mercure de France: "...Les plus ardents partisans de la revanche, Mme Adam, Déroulède, Voguë, entraînèrent l'engouement des foules et, à la longue, l'approbation des ministres et des députés. On a vu depuis quelle garantie et quel secours a offerts une telle alliance. Et, précisément, au début de la $\mathrm{III}^{\mathrm{e}}$ République, les hommes d'État français, Gambetta, Challemel, Lacour, Spuller, Grévy, Ferry, mieux renseignés que leurs successeurs sur la valeur éventuelle d'une alliance franco-russe, se refusaient à suivre toute suggestion en sa faveur. » (Edouard Krakowski, Le problème des Alliances au début de la III République; Mercure, 1-9-31.) Les républicains étaient donc, au début, contre l'alliance russe, proposée et soutenue par des réactionnaires et des cléricaux tels que Mme Adam, spirituelle collaboratrice des Jésuites ! 
méthodiques, il les avait fait enregistrer sur les fameuses fiches. Pour cléricaliser toute le haute armée, il a suffi d'une année à M. MiLlERAND, sans connaissance du personnel, sans fiches, simplement en s'abandonnant aux conseils d'un cabinet et d'un état-major réactionnaires. »-(Le Courrier Européen, 23-5-1913) ${ }^{6}$.

On ne sera pas surpris d'apprendre que la campagne contre le combisme était dirigée par le Vatican. Mais je tiens à faire remarquer que, dans cette campagne, le général ANDRÉ était particulièrement visé. Sans doute craignait-on, à Rome, que le "général républicain », balayant les incapables et les jésuites de l'État-Major, n'arriva à doter la France d'une armée vraiment nationale - et efficace ? En tout cas, Mgr Montagnini écrivait, le 2 novembre 1904 : «Si on ne peut réussir à faire tomber le cabinet entier, on fera tout ce qu'on pourra pour obliger André à partir. On prévoit pour vendredi prochain une séance tumultueuse. » (Lettre à MERRY del VAL.)

C'était le scandale anti-maçonnique des fiches, l'affaire SYVETON et autres manœuvres jésuites.

De l'autre côté, en Allemagne, c'étaient également les catholiques qui se distinguaient par le chauvinisme ardent. Le Centre catholique ne fut-il pas pendant longtemps (et il l'est devenu) l'arbitre de la situation au Reichstag, étant donné qu'on ne pouvait former de majorité sans son concours? Il porte donc une lourde responsabilité dans les origines de la guerre, si celle-ci sont imputables à l'Allemagne, comme le prétendent non chauvins à nous...

La Gazette de Cologne, organe du Centre, a inventé la théorie de l'Otage, selon laquelle, en cas de guerre entre l'Allemagne et

6 Le même journal publiait un tableau suggestif. D'un côté, l'État-Major avant Millerand (1911) ; en regard, l'État-Major après Millerand (1913). La comparaison est suggestive. Tant à l'État-Major Général qu'au Conseil Supérieur de la Guerre, les généraux républicains avaient été remplacés par des cléricaux et des réactionnaires. L'État-Major était devenu une jésuitière.

Il l'est d'ailleurs resté. Le limogeage de Pétain et son remplacement par Weygand («Il est enfoncé dans les curés jusqu'au cou», disait Clemenceau) ont définitivement livré l'armée de la République au Parti du Vatican. 
l'Angleterre, la France devrait être envahie de suite (afin de servir d'otage...).

Le célèbre homme politique catholique ERZBERGER (dont la mort tragique a racheté partiellement les cruelles erreurs) n'écrivait-il pas, le 17 septembre 1914, au général Falkenhayn, ministre de la Guerre allemand :

« Il ne faut pas s'inquiéter de porter atteinte au droit des peuples ni de violer les lois de l'humanité. De tels sentiments passent aujourd'hui au second plan. » Et dans le tag du 21 octobre de la même année, il disait :

«Si l'on trouvait un moyen d'anéantir la ville de Londres tout entière, il y aurait plus d'humanité à l'employer qu'à laisser couler, sur le champ de bataille, le sang d'un seul soldat allemand. Faire preuve de faiblesse et de sentimentalité pendant la guerre, ce serait faire preuve d'une stupidité impardonnable. »(Cité par La Croix, 14-721). ${ }^{7}$

7 M. Gaston Doumergue (voilà un témoignage que l'on ne pourra suspecter !) a lui-même raconté qu' «en 1887, les députés catholiques du Reichstag refusaient de voter les crédits contre la France : le Pape leur enjoignit de les voter immédiatement» - (Cité par Albert LETELLIER.)

Le même auteur dit encore : «A l'amphithéâtre Richelieu, de la Sorbonne, M. Renouvin enseignait, le 11 mars 1930, que le Parti catholique du Reichstag, en parfait accord avec le Pape, avait fait accepter la guerre sous-marine en mars 1916... Ce serait après une pression de Rome que les catholiques du Reichstag l'auraient votée.»

Du reste, les catholiques allemands ont toujours été les bellicistes les plus enragés - et cela continue. D'après M. Prudhommeaux (La Paix par le Droit), « les quatre cinquièmes des professeurs des Universités et Gymnases de Prusse, sont favorables au rétablissement des HoHENZOLLERN ; et, en Bavière, le nombre de maîtres de l'enseignement supérieur et secondaire gagnés à la réaction la plus violente atteint et dépasse peut-être 95 pour cent ». Or, la Bavière est fougueusement catholique ! Pourquoi M. SANGNIER ne va-t-il pas convertir au pacifisme ses congénères bavarois, au lieu d'endormir le prolétariat français à l'aide de ses doctrines funestes?

L'Action Française (1-2-29) annonce que le cardinal JACOBINI fut chargé (en janvier 1887), par LÉON XIII, « de faire savoir discrètement aux membres du centre et aux députés catholiques d'Alsace et de Lorraine au Reichstag que 
Quatre mois plus tard, le même Erzberger partait à Rome, auprès du Saint-père, pour y chercher les mots d'ordre! Les paroles odieuses qu'on vient de lire n'en ont que plus de signification. Si le Vatican avait été sincèrement pacifiste, comme on ose le prétendre aujourd'hui, comment aurait-il toléré, avant et après 1914, que les catholiques soient précisément les plus violents adversaires de la paix, aussi bien en France qu'en Allemagne?

Sa Sainteté désirait qu'ils votassent le projet de septennat militaire, proposé par BISMARCK. »" 


\section{IV \\ POURQUOI L'ÉGLISE DÉSIRAIT- ELLE LA GUERRE?}

$\underline{\text { Retour à la table des matières }}$

Arrivons à présent à 1914, négligeant une foule de documents et de faits que nous pourrions glaner encore à travers ces quarante années, à l'appui de notre thèse. La présente étude doit être brève et se bornera par conséquent à retenir les argument essentiels.

L'Église romaine avait-elle un intérêt, en 1914, à provoquer ou à faciliter un conflit international?

Je réponds par l'affirmative, dans hésiter.

L'Église avait triplement intérêt à ce que la guerre éclatât.

$1^{\circ}$ Parce que la guerre permet toujours de « ranimer la foi ». Par les douleurs et les deuils qu'elle entraîne, elle jette le désarroi dans les consciences. L'individu, faible et désemparé, éprouve le besoin d'invoquer un Protecteur tout puissant. Dès le mois d'août 1914, les églises, désertées jusqu'alors, se sont spontanément remplies. 
$2^{\circ}$ Parce que l'Église escomptait la défaite de la France laïque et républicaine et pensait pouvoir instaurer, à la faveur de cette défaite, un régime monarchique et clérical.

$3^{\circ}$ Parce que le Vatican savait fort bien que le désarroi, qui allait régner dans toute l'Europe, lui serait profitable. GuILLAUME II avait promis au pape, s'il était vainqueur, de rétablir le pouvoir temporel de la Papauté (n'est-il pas curieux de voir un Mussolini remplir les promesses du Kaiser déchu et poursuivre en Europe la politique de provocation néfaste que le Kaiser poursuivait?)

Ces trois points sont faciles à démontrer. L'Église se vante ellemême, orgueilleusement, des progrès considérables qu'elle a réalisés depuis 1914. En France, en particulier, elle a retrouvé un prestige et une influence incontestables - grâce à la faiblesse et même à la complicité d'un grand nombre de politiciens pseudo-républicains.

Sur le second point les calculs des Jésuites ont été déjoués. La France n'a pas été vaincue, mais il s'en est fallu de bien peu. En septembre 1914, les Allemands étaient aux portes de Paris et la capitale serait tombée fatalement entre leurs mains, sans la faute stupide de tactique de leur général Von KLUCK ${ }^{8}$.

8 Et si la France a été sauvée de la défaite en septembre 1914, elle ne le doit assurément pas aux lumières de son État-Major de Jésuites... et d'incapables. Ces brillants généraux que l'on flagorne semblent avoir tout combiné au contraire (peut-être sur l'instigation de leurs confesseurs...) pour que la France fut écrasée.

JAURÈS les avait prévenus que l'invasion allemande, vraisemblablement, arriverait par le Nord. Nos généraux n'avaient pas voulu tenir compte de ces avertissements réitérés et les Allemands, après avoir traversé la Belgique, purent arriver librement aux portes de Paris. La victoire de la Marne sauva la France, mais grâce à qui ? Sinon à GALLIÉNI, qui désobéit à JofFRE, comme SARRAIL avait dû désobéir pour sauver Verdun!

Si CASTElnau n'avait pas démantelé la frontière du Nord, les Allemands ne seraient pas venus sur la Marne. Et c'est un général républicain qui essaya vainement de réagir contre ces tactiques imbéciles. Il en fut récompensé par les pires calomnies de la part des cléricaux.

Partout le gâchis, l'incurie, l'incompétence.

On accusera le Parlement républicain d'avoir voté des crédits militaires insuffisants? Hélas ! terrorisés par les campagnes de presse que déclenchaient 
la Haute Banque et la Métallurgie, particulièrement dans les journaux de droite, nos parlementaires votaient tout ce qu'on leur demandait - et l'ÉtatMajor engloutit des milliards inutilement, sans assurer la défense du pays. (Notons que l'adoption de l'artillerie lourde, proposée par le général républicain ANDRÉ, fut vivement combattue par la réaction. Les sénateurs réactionnaires amis de l'État-Major (duc d'AUDIFFRET-PASQUIER, comte d'AUNAY, comte de Blois, baron de CourCel, de LAMARzelle, toute le fine fleur de l'Église !) votèrent contre et le canon lourd fut repoussé. Tous les spécialistes reconnaissent qu'il fit cruellement défaut au début de la guerre. Ceci se passait en 1903, sous le ministère COMBES. Alors?

Dans un récent ouvrage, POINCARÉ écrit :

« Nous ne voulions pas la guerre, mais en attendant l'époque incertaine où les progrès de l'humanité permettaient de conserver la paix sans en assurer la défense, nous n'entendions pas commettre le crime de laisser la Triple Entente désarmée en face d'une Triple Alliance armée jusqu'aux dents. "

Cette assertion tendrait à faire croire que l'Allemagne et l'Autriche faisaient des préparatifs de guerre, alors que l'Entente négligeait de se préparer. Rien n'est plus faux.

Pendant les vingt années qui ont précédé la guerre, les dépenses faites par les Empires centraux ont été de 477 millions de livres sterling (près de douze milliards de francs) moins élevées que les dépenses correspondantes faites par la France et la Russie (Chiffres donnés par le député SNOWDEN à la Chambre des Communes, le 20-2-1917).

En 1912, le budget (Guerre et Marine) s'élevait : pour la Russie, à 2 milliards 52 millions; pour la France, à 1 milliard 343 millions; pour l'Angleterre, à 1 milliard 779 millions.

Au total, pour l'entente : 5 milliards 174 millions.

Tandis que, pour les Empires centraux, la même année, le budget (Guerre et Marine) ne s'élevait qu'à 1755000000 pour l'Allemagne, 822 Millions pour l'Autriche. Même en y comprenant l'Italie, dont la défection était cependant visible d'ores et déjà, la Triple Alliance ne dépensait donc, en tout, que 3 milliards 326 millions - soit 1 milliard 848 millions de moins, dans une seule année, que les gouvernements de l'Entente.

L'histoire du bassin de Briey mériterait également d'être rappelée.

La guerre a duré deux ans de plus, parce qu'on avait donné l'ordre de ne pas bombarder les mines de Briey, dont les Allemands s'étaient emparés! Privée du minerai de Briey, l'Allemagne eut été impuissante à continuer la lutte.

Qui a donné l'ordre de respecter Briey, faisant bon marché, non seulement du salut de la France, mais de la vie de plusieurs centaines de milliers de Français, inutilement et criminellement massacrés ? Nous ignorons les noms de ces éminents patriotes, mais nous savons, par contre, que MM François de WENDEL (député de Briey) et Guy de WENDEL (député de Metz, la ville la plus cléricale de France !), puissante dynastie dont la fortune est évaluée à dix 
Il a fallu quatre années de lutte ardente, et le concours de nombreux alliés, pour vaincre l'Allemagne.

D'ailleurs, dès que la Papauté se fut rendu compte que ses calculs étaient déjoués, que la France impie (qui avait chassé les Congrégations et voté la Séparation) ne serait pas vaincue et humiliée, elle modifia ses batteries. Alors qu'elle n'avait pu masquer ses sympathies germanophiles dans la première partie de la guerre, elle affecta de faire risette aux Alliés, à partir du moment où la fortune des armes sembla vouloir changer de camp.

Quant au troisième point précité, je n'y insiste pas, car personne ne contredira que l'Église ait été, dans le monde entier, le grand profiteur de la guerre et qu'elle ait fortifié ses positions, même dans les pays non catholiques ${ }^{9}$.

milliards, maîtres du Comité des Forges, sont des aristocrates entièrement dévoués à l'Église et qu'ils doivent certainement manœuvrer toujours en plein accord avec le Vatican.

En dépit de ses grimaces faussement démocratiques, l'Église travaille toujours pour les privilégiés.

9 Le nombre des pays représentés par un ambassadeur auprès du Vatican a plus que doublé depuis la guerre, de nombreux gouvernements ont noué (ou renoué) des relations diplomatiques avec la Papauté, parce qu'ils ont compris que la Vatican était un nid d'intrigues. C'est pourquoi les « Concordats » (les peuples en font toujours les frais, malheureusement) se sont multipliés.

«Le cardinal GASPARRI qui fut secrétaire d'État du Vatican sous BENOîT XV, de 1914 à 1922 et sous PIE XI de 1922 à 1930, fut le négociateur officiel d'une série de pactes concordataires avec divers États. Déjà, pendant la guerre, époque peu propice aux négociations de cet ordre, le Vatican insistait sur les liens d'affection unissant Rome et la France, et sur la nécessité de rétablir dans ce pays la paix religieuse, et escomptait le rétablissement éventuel des relations diplomatique que la loi de séparation avait rompues. »(Edouard Helsey, la Pensée du Pape, interview du cardinal GaSPARri, 31 août 1916).

«Le même GASPARri écrivait à Denys COCHIN, ministre d'État, le 29 juin 1917, sur le protectorat catholique de Echelles du Levant en prévision de la disparition possible de la domination turque. »

«En 1921, l'ambassade auprès du Vatican était rétablie. Et dans les années suivantes, dix pactes concordataires étaient conclus : avec la Lettonie, 30 mars 1930 ; la Bavière, 29 mars 1924 ; la Pologne, 10 février 1925 ; la Lithuanie, 
Ayant démontré : $1^{\circ}$ Que 1'Église avait intérêt à faciliter la guerre ; $2^{\circ}$ qu'elle en a retiré d'incontestables bénéfices moraux et matériels; nous allons rechercher les preuves effectives de sa participation dans les origines du conflit.

27 septembre 1927 ; la France, 4 décembre 1928 ; (honneurs liturgiques dans le Proche-orient); la Tchécoslovaquie, 2 février 1928; le Portugal, 15 avril 1928 (organisation ecclésiastique des Indes Orientales); l'Italie, 11 février 1929 ; la Roumanie, 1927-28-29 ; la Prusse, 14 juin 1929. — (La Défense Laïque).

En envoyant les ambassadeurs à Rome, les gouvernements s'imaginent, bien à tort, servir leurs intérêts. Grosse erreur! Le défunt député NOBLEMAIRE, qui n'était pas anticlérical (c'était un gros brasseur d'affaires, un des esprits les plus modernes de la grande bourgeoisie), n'a-t-il pas déclaré, lors du procès JUDET, que JUDET s'était fait « rouler» à Rome - et n'a-t-il pas ajouté : Ce sont des choses qui arrivent à tout le monde, et même, en ce moment, à des gouvernements très bien! (Rires.)

La Cour pontificale est, en effet, le théâtre de toutes les duplicités de toutes les hypocrisies, des manœuvres les plus tortueuses. Quiconque y met le pied est certain d'être roulé et la France (à laquelle M. NoBLEMAIRE faisait allusion) a eu bien tort de renouer des relations avec le Vatican. A noter que M. NOBLEMAIRE fut attaché militaire en Italie pendant la guerre et connaissait parfaitement le rôle joué par la Papauté. 


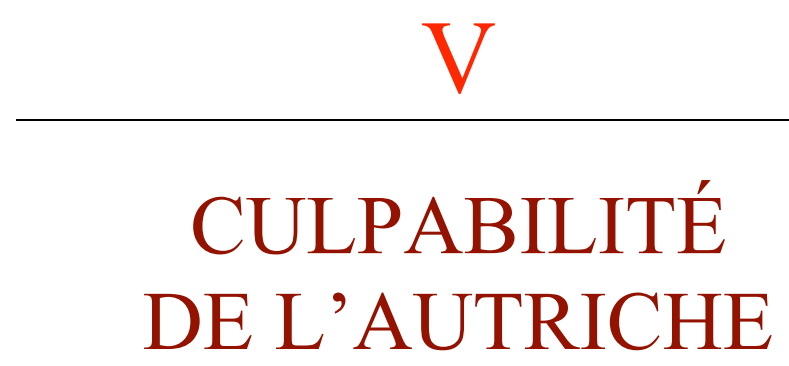

$\underline{\text { Retour à la table des matières }}$

Première hypothèse : Le Pape était-il derrière l'Autriche?

On a accusé l'Autriche d'être la principale responsable. En envoyant à la Serbie, au lendemain de l'attentat de Seravejo, un ultimatum inacceptable, elle rendait la guerre inévitable ${ }^{10}$.

La responsabilité de FRANÇOIS-JosEPH est si gênante pour l'Église (c'était le monarque le plus catholique du monde entier ! Il était intervenu, avec son droit de veto, dans l'élection du Pape PIE X), que des efforts sont tentés pour la diminuer ou la nier. Ainsi, le comte Jean de PANGE (Croix, 9-9-30), affirme que l'Empereur d'Autriche était

10 Je n'imiterai pas nos adversaires et je n'accuserai pas l'Église d'avoir fomenté l'attentat de Seravejo (les cléricaux, en effet, ont imaginé de rejeter sur... la Franc-Maçonnerie l'organisation et l'exécution de l'assassinat de l'archiduc d'Autriche et de sa femme !). Ce qui n'est pas contestable, c'est que le gouvernement serbe a trempé d'une façon quasi-officielle dans la préparation de cet assassinat, la fourniture des armes et des bombes, etc... Mais si l'Église n'a pas fomenté cet assassinat, elle a su en retirer le principal profit ! 
«prisonnier» des Hongrois, qui lui imposaient une politique antislave. Mais le Hongrois (demandez-le à l'amiral HoRTHY et à... l'abbé BERGEY !) ne sont-ils pas, aujourd'hui encore, parmi les plus zélés défenseurs de l’Église?

D'autre part, M. Ernest Bota a publié dans La République (3-930) une intéressante étude, accusant également la Hongrie. Le comte TISZA aurait trempé dans la préparation de l'assassinat de l'archiduc Ferdinand ; prévenu de ce qui se tramait à Seravejo, il aurait empêché ses subordonnés d'intervenir pour arrêter l'attentat qui menaçait son maître !

Est-il nécessaire de faire remarquer que cette thèse, si elle n'innocente pas la Serbie, n'innocente pas non plus le Vatican? Au contraire ! Derrière la Hongrie cléricale, comme derrière le vieux dévot François-Joseph, ne devinez-vous pas la main sournoise des hommes noirs, qui manœuvraient internationalement, ne l'oubliez pas... ${ }^{11}$.

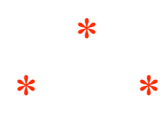

Quelques autres documents vont nous éclairer sur la psychologie éminemment cléricale des dirigeants de l'Empire austro-hongrois -

11 Il n'est pas douteux que la Hongrie, aujourd'hui encore, soit dirigée par les Jésuites : "C'est le Vatican qui a tramé le complot de la restauration. Il a réconcilié les monarchistes hongrois, autrichiens et bavarois, c'est-à-dire les WitTElsBACH et les HabSBOURG. Ce rapprochement entre le komprinz RuPPRECHT de Bavière et l'ex-impératrice ZITA est l'œuvre du prince Aloys zu LeWENSTEIn, parent des HABSBOURG et des WitTELSBAH, président des congrégations catholiques allemandes et qui, en 1925, collabora avec les princes de l'Église à l'établissement du programme d'éducation du jeune OTTO. » (Charles REBER, La Lumière, 22-8-31.) M. REBER, très documenté, dévoile l'existence d'un vaste complot monarchiste organisé par les Jésuites dans toute l'Europe Centrale. Ce qui n'empêche pas le gouvernement français de prêter des centaines de millions aux dictateurs hongrois - toujours pour être agréable au Vatican! 
et nous aider à comprendre l'immense influence que le Pape pouvait y exercer.

Évoquant le drame de Mayerling (suicide de l'archiduc RodOLPHE en 1889), M. PALÉOlogue est amené à soulever, dans Le Temps, quelques dessous intéressants de la politique contemporaine. Les faits qu'il cite sont, par eux-mêmes, peu importants, mais leurs répercussions ont été formidables !

Voici une partie d'une conversation confidentielle que l'auteur échangea avec l'Impératrice Eugénie en 1906 :

En apprenant la mort violente de son fils (1889), l'Empereur FRANÇOIS-JOSEPH télégraphia immédiatement eu Pape LÉON XIII pour le supplier d'autoriser les obsèques religieuses, malgré le suicide ; il ajoutait que, s'il n'obtenait cette autorisation, il abdiquerait la couronne. Fort troublé par le cas de conscience qui se posait devant lui, LÉON XIII consulta le cardinal RAMPOLLA. L'opinion du secrétaire d'État fut catégorique ; les conditions dans lesquelles l'Archiduc RoDOLPHE avait mis fin à ses jours ne permettaient pas qu'on l'inhumât selon les rites de l'Église. Le Saint-Père chercha une transaction. A défaut des obsèques solennelles, qui auraient en effet scandalisé beaucoup d'âmes, ne pourrait-on accorder à l'Archiduc RODOLPHE des funérailles intimes, secrètes, dans la chapelle de la Hofburg ? Le cardinal RAMPOLLA maintînt avec énergie son opinion première. De plus en plus troublé, LÉON XIII passa outre et répondit à l'Empereur qu'il autorisait l'aumônier de la Cour à célébrer des funérailles secrètes. Mais FRANÇOIS-JOSEPH insista de nouveau pour des obsèques solennelles; sinon il abdiquerait. Dans la grande pitié de son cœur, LÉON XIII finit par céder aux supplications du vieux souverain, que la vie avait déjà tant éprouvé. Les obsèques de l'Archiduc furent donc célébrées avec toutes les pompes rituelles. Et ce fut une grande consolation pour le pauvre François-Joseph qui, dans son for intérieur, avait déjà abdiqué... Malheureusement, il connut l'opiniâtreté résistante qu'avait opposée RAMPOLLA, et il eut la faiblesse de lui en garder rancune comme d'une offense personnelle... Treize ans et demi plus tard, LÉON XIII mourait. Vous vous rappelez avec quelle ferveur tout ce qu'il a d'esprits larges et libéraux dans le monde catholique souhaitait l'élection du cardinal RAMPOLLA ; mais vous vous rappelez 
aussi que, le dernier jour du Conclave, à l'instant décisif, le cardinalarchevêque de Cracovie prononça, au nom de l'Empereur FrançOISJOSEPH, un veto d'exclusion contre le cardinal RAMPOLLA. Et le cardinal SARTO fut élu! (Mercure, 15-7-23).

Le cardinal SARTO (PIE X) était encore Pape en 1914, au moment où se déclencha la guerre mondiale. Créature de l'Autriche, élu grâce à l'Empereur FRANÇOIS-JOSEPH, comment aurait-il pu réagir contre la politique de celui-ci ? Il la soutint au contraire de toutes ses forces; il poussa à la guerre — on l'a vu par le télégramme du baron Ritter.

Ainsi tout s'explique... Quiconque veut se donner la peine de suivre avec patience, dans le dédale de ses obscurités, la politique romaine, sera de notre avis : le Vatican est le plus grand obstacle au progrès de l'Europe.

Revenons à l'Autriche et à son influence sur la Papauté ? Voici ce qu'en dit la revue Politica, absolument neutre au point de vue politique et qui se borne à publier des études documentaires et objectives, pleines d'intérêt du reste. L'auteur de l'article rappelle qu'entre l'Autriche et la Papauté une longue et solide alliance existait. L'Autriche témoignait au Pape une «exceptionnelle déférence » et elle accordait des avantages considérables au clergé, au haut degré surtout (comme de juste !) Et il ajoute :

«...Il y avait bien là de quoi établir entre la cause de l'Église et celle de l'Autriche les liens les plus forts, de quoi assurer à la monarchie l'appui tantôt prudent et discret, tantôt au contraire hardi et déclaré, de la politique romaine. Il y a là aussi de quoi expliquer, après l'échec final, bien des regrets, une foi obstinée aux légendes les moins croyables, des rancunes, des espoirs de revanche, toutes les incroyables illusions qui, en matière d'Autriche ou d'Europe centrale, se maintiennent dans tant de milieux catholiques. ॥ (Politica, septembre 1923).

Les responsabilités doivent être partagées entre les divers gouvernements, tous manœuvrés, plus ou moins, par les Jésuites. 
La Russie, qui excitait et poussait la Serbie, mobilisa la première. Et la France, qui assurait au tsar, par la bouche de Poincaré, qu'elle était prête à remplir ses devoirs fidèle et vaillante alliée, ne tarda pas à la suivre... 


\section{VI \\ QU'A FAIT PIE X POUR MODÉRER L'AUTRICHE?}

Ne chicanons pas et prenons la thèse officielle: C'est l'Autriche qui a voulu la guerre, poussée d'ailleurs par l'Allemagne, laquelle se sentait " encerclée » depuis longtemps et n'attendait qu'une occasion propice pour déclencher une conflagration.

Nous posons alors la question suivante : Qu'a fait le Vatican pour retenir l'Autriche? pour l'empêcher de provoquer la Serbie? pour lui demander d'atténuer les termes de son ultimatum, ce qui eut permis sans doute de maintenir la paix ? Ces questions nettes et précises, je les ai posées souvent à des contradicteurs cléricaux. Je n'ai jamais pu obtenir que les deux seules réponses suivantes :

$1^{\circ}$ Le Pape ne voulait pas la guerre. La preuve ? C'est qu'il est mort de chagrin, dès le début des hostilités...

$2^{\circ}$ L'Empereur d'Autriche ayant demandé au pape de bénir ses armées, le pape aurait répondu : «Je bénis la Paix!» 
On avouera que ces deux argument sont un peu... faibles.

Comment pouvons-nous savoir si PIE X est réellement mort de chagrin ? Son décès imprévu (car le Pape jouissait d'une excellente santé) permet toutes les hypothèses, c'est évident, mais... cette bonne santé rend très peu plausible l'explication des cléricaux. On a rarement vu un homme solide et bien portant tué par le chagrin. PIE $X$ était de race paysanne et forte, ce que nous savons de lui permet de supposer qu'il n'était pas exceptionnellement sensible et émotif et je répète que cette hypothèse me paraît complètement dénuée de fondement.

Cette hypothèse serait du reste un peu humiliante... pour le Christianisme ! Le Pape serait mort de chagrin, tout seul. Et les cardinaux, archevêques, évêques, curés, la multitude des fidèles et des croyants ? Le Pape eut donc été, dans le monde entier, le seul vrai chrétien, sensible, délicat, sincère? Et les autres alors?

Devant la pauvreté de cette thèse, je comprends que l'on ait cherché d'autres explications. Je ne mentionnerai que celle de l'abbé DANIEL, auteur du livre Le Baptême du Sang. Cet auteur déclare que le Pape PIE $\mathrm{X}$ a été vraisemblablement empoisonné par les jésuites, précisément parce qu'il n'était pas partisan de la guerre.

Grave affirmation! On demandera des preuves. Comment les fournir? Les secrets du Vatican sont bien gardés et les traces du crime, si crime il y eut, ont certainement été effacées sur l'heure. Les disciples de LOYOLA sont discrets ; ils l'ont souvent montré. En tout cas, ce ne serait pas la première fois que des disparitions mystérieuses se produiraient au Vatican et le poison y fit souvent son œuvre sournoise...

Mais attention! Vous allez me faire une objection : si le Pape a été empoisonné parce qu'il voulait empêcher la guerre, comment pouvezvous dire que l'Église est responsable du conflit?

Ma réponse sera simple. Le Pape est le chef nominal de l'Église, mais il n'est pas le seul à gouverner. Il lui arrive ce qui arrive à la plupart des gouvernants, il est manœuvré par ses bureaux et son entou- 
rage. N'oublions pas que la bureaucratie papale, la Curie romaine, constitue la plus importante (et sans doute la plus avide, ce qui n'est pas peu dire !) bureaucratie du monde.

Derrière la Curie, derrière les bureaucrates et les cardinaux, derrière le Pape lui-même, il y a un autre pouvoir qui les domine tous et qui s'appelle la Compagnie de Jésus.

Le Pape blanc n'est qu'un jouet entre les mains du Pape noir !

Est-ce le Pape noir qui a fait empoisonner le Pape blanc, afin de réaliser le rêve rouge des Jésuites, déchaîner le massacre et raffermir la puissance politique de l'Église, compromise par les progrès de la Laïcité ?

La chose n'est pas invraisemblable, car les Jésuites en ont tué bien d'autres.

Il appartient au lecteur de choisir entre les deux thèses.

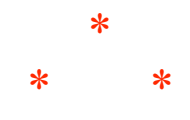

Si l'on accepte l'affirmation que PIE X est réellement mort de chagrin, il faudra nous expliquer ce qu'il a tenté, avant de mourir, en faveur de la Paix.

Puisqu'il aimait si passionnément la France et la Paix, qu'a-t-il fait en leur faveur? On ne nous l'a jamais dit !

\section{Il n'a pas même osé menacer FrançoIs-JosepH de l'excommunication !}

On se contente d'assurer qu'il s'est laissé abattre par la douleur, sans rien pouvoir faire d'utile. Quelle faiblesse de caractère, et chez un homme qui était considéré comme le pasteur suprême de tous les chrétiens, le représentant direct de Dieu sur la terre, le « vice-Dieu », comme dit La Croix! 
Étant donné la grande autorité morale dont il est investi aux yeux des chrétiens, s'il avait parlé, s'il avait protesté, sa voix n'aurait pu être étouffée et nous l'aurions entendue. Il n'en a rien été.

Qu'on cesse donc de nous présenter comme une poule mouillée, ce vieillard borné, têtu, autoritaire, qui fut le pourfendeur des modernistes et qui provoqua la Séparation par ses maladresses et ses brutalités. 


\section{VII \\ LE VATICAN A POUSSÉ À LA GUERRE}

Laissons de côté la personnalité de PIE X et les causes, réelles ou supposées, de sa mort.

Certains documents permettent de connaître le rôle joué par le Vatican à la veille de la guerre. Ces documents étaient destinés à demeurer secrets ; ils n'ont été connus qu'au lendemain des révolutions populaires dans les Empires centraux, qui ont permis de pénétrer dans les archives gouvernementales.

Le premier de ces documents est le fameux télégramme du baron de RITTER, dont l'authenticité n'a jamais été mise en doute. En voici le texte :

(Il s'agit d'un télégramme adressé par la légation de Bavière à la Cour pontificale, vers la fin de juillet 1914).

« Baron RitTer, au gouvernement bavarois. Le Pape (PIE X) approuve une action énergique de l'Autriche contre la Serbie. 
Le cardinal secrétaire d'État (MERRY del VAL) espère que cette fois l'Autriche montrera la résolution voulue. Il se demande si l'Autriche trouvera jamais une meilleure occasion de faire la guerre que lorsqu'il s'agit de repousser par les armes les entreprises d'une puissance extérieure qui a fomenté le meurtre de l'archiduc, et qui met en péril l'existence de la monarchie dualiste.

« Les déclarations du cardinal secrétaire d’État montrent les appréhensions de la Curie romaine au sujet du panslavisme.

Signé : RITTER. »

Impossible d'équivoquer sur ce texte. Il est clair, catégorique, formel.

«Le Pape approuve une action énergique de l'Autriche contre la Serbie. »

Donc le Pape approuve la guerre.

Et le Pape sait très bien («l'homme le mieux renseigné du monde ») que cette guerre ne sera pas localisée dans les Balkans. Il sait que la Russie interviendra et que la France suivra, il sait que l'Allemagne soutiendra l'Autriche, que toute l'Europe, par conséquent, sera mise à feu et à sang... Il sait tout cela - et il approuve quand même, étant donné que l'Autriche ne retrouverait jamais une aussi bonne occasion de faire la guerre !

Je pourrai poser la plume et considérer que ma tâche est terminée. Le document RITTER, à lui seul, suffit à démontrer lumineusement la culpabilité du Vatican.

Les Jésuites, qui sont très habiles, n'avaient pas prévu que les révolutions autrichienne, russe et allemande permettraient aux profanes de connaître des documents aussi compromettants que celui-là !

En voici un autre. Il était destiné, comme la dépêche du baron RITTER, à demeurer enfoui dans les Archives gouvernementales : 
Voici le passage principal d'une lettre du comte Pallfy d'ERDOD, conseiller de légation à l'ambassade d'Autriche-Hongrie auprès du Saint-Siège. Cette lettre est datée du 29 juillet 1914 - quelques jours seulement avant la déclaration de guerre :

«... Au cours de la visite que je fis, il y a deux jours, au cardinal, secrétaire d'État, celui-ci dirigea naturellement la conversation sur les grands problèmes et sur les questions qui préoccupent aujourd'hui l'Europe. Mais, dans les observations de Son Éminence, il était impossible de sentir un esprit particulier d'indulgence et de conciliation. Tout en caractérisant d'extrêmement rude la note adressée à la Serbie, il l'approuvait néanmoins sans aucune réserve et exprimait en même temps, de manière indirecte, l'espoir que la monarchie irait jusqu'au bout. Certes, pensait le cardinal, il était dommage que la Serbie n'eût pas été humiliée* (kingemacht) beaucoup plus tôt, car alors cela aurait peut-être pu se faire sans mettre en jeu, comme aujourd'hui des possibilités tellement immenses.

"Cette déclaration correspond aussi à la façon de penser du Pape, car, au cours de ces dernières années, sa Sainteté a exprimé à plusieurs reprises le regret que l'Autriche-Hongrie ait négligé de «châtier » son dangereux voisin danubien... »-(Pallfy d'ERDOD).

Dans une autre lettre, dont l'auteur est le Prince Jean SchONBURg luimême (ambassadeur d'Autriche-Hongrie auprès du Saint-Siège), nous trouvons l'aveu suivant : Le Pape lui a promis (février 1915) d'agir de toutes ses forces pour que l'Italie reste neutre et n'intervienne pas dans le conflit. Par amour de la paix ? Non pas. Le Pape avoue « avec la sincérité la plus parfaite qu'en cela il s'agissait pour lui, tout autant que l'AutricheHongrie, de la situation de la Papauté. »

Le prince SCHONBURG, dans une lettre postérieure (16 mars 1915) montre que toutes les dispositions sont prises entre lui et le pape pour que leurs entrevues et tractations demeurent absolument secrètes :

"Ainsi que je me suis permis d'en convenir avec Sa Sainteté, je demanderai mes audiences à venir, sans désigner expressément mon nom, par téléphone de l'« Anticamera » (non plus comme jusqu'à présent par l'intermédiaire du cardinal secrétaire d'État), et autant que possible pour une heure qui n'attire pas l'attention. Sa Sainteté conclut que je pourrais venir chaque fois que je voudrais et aussi souvent que je le désirerais. Elle sera toujours heureuse de recevoir d'éventuelles communications et d'examiner ensuite avec moi ce qui pourrait se faire en notre intérêt... »

* Les mots en italique sont soulignés dans le texte original 
On aura remarqué que les termes de la lettre de M. Pallfy d'ERDOD présentent une grande analogie avec ceux du télégramme RITTER. On y constate franchement que la papauté pousse l'Autriche de toutes forces contre la Serbie, sans méconnaître les répercussions immenses qui vont en résulter pour le monde.

La Papauté a agi en connaissance de cause, elle a su ce qu'elle faisait. Elle voulait la guerre dans toute son horreur, afin de ressaisir les âmes qui lui échappaient, afin de châtier la France impie, afin de rétablir le pouvoir temporel parmi les ruines et les douleurs de l'hécatombe savamment préparée par les hommes noirs... 


\section{VIII \\ HYPOCRISIE DE LA PRÉTENDUE NEUTRALITÉ PAPALE}

$\underline{\text { Retour à la table des matières }}$

Dès 1880, le Vatican s'est appliqué à montrer au monde qu'une «nation sans Dieu» est châtiée...

Il a donc puissamment travaillé à réaliser le châtiment divin, en suscitant contre la France, par toute la terre, le plus de mépris possible...

\section{RIEFFEL}

(Cité par Jean Izoulet, professeur au Collège de France : Foi et Vie, p. 263.)

Devant des documents aussi éloquents, que pèse la misérable argumentation des Jésuites ? et en particulier cette anecdote attribuant à PIE X le refus de bénir l'armée autrichienne et répondant au vieil empereur : « Je bénis la Paix!»

La déclaration n'était pas bien compromettante. 
Le pape ne pouvait pas bénir l'armée d'Autriche officiellement. C'eut été commettre une maladresse très préjudiciable à l'Église. C'était «prendre parti » entre les belligérants — et l'on sait que la Papauté s'y est toujours refusée, au moins publiquement. Elle s'est abritée derrière la plus hypocrite neutralité (au point de ne pas même vouloir blâmer la scandaleuse violation de neutralité belge par les Allemands), parce qu'elle avait des clients dans les deux camps et qu'elle ne voulait mécontenter ni les uns ni les autres.

Le Vatican ne pouvait pas plus donner de bénédiction aux armées austro-allemandes qu'aux armées françaises ou belges, mais il avait, dans chaque pays, des représentants directs, évêques, archevêques et curés, qui ne se privaient pas de prendre position, qui «poussaient» patriotiquement à la continuation de la tuerie, car ils y avaient tous intérêt. Plus la guerre se prolongeait, saignant et abrutissant les peuples, plus la puissance des clergés prenait de force et pouvait s'épanouir insolemment parmi les ruines amoncelées.

L'argument de la «neutralité », invoqué par ceux qui prétendent que la Papauté a servi la cause de la paix, est absolument sans valeur.

En réalité, le Vatican a servi sa propre cause, comme toujours.

Il a été neutre, tout au moins théoriquement et officiellement (car nous ignorons le détail des intrigues et des manœuvres qui se sont multipliées, certainement pendant quatre années) parce qu'il ne pouvait pas faire autrement. Lier sa cause à l'un ou à l'autre des belligérants, c'était s'exposer à être entraîné avec lui dans la défaite - et le Vatican ne voulait à aucun prix être vaincu! Il tenait au contraire, quelle que fut l'issue du conflit, à conserver intacte et à accroître autant que possible la puissance matérielle et morale de son Église.

Un fait est d'ailleurs frappant : le Pape BENOÎT XV, neutre jusqu'au bout des ongles, n'a jamais rien fait, non pas seulement pour imposer cette neutralité à ses évêques des différentes nations, mais 
pour atténuer leur zèle jusqu'auboutiste et guerrier — qui atteignait souvent la frénésie la plus folle ${ }^{12}$.

Et pourtant, le Pape est le chef suprême et incontesté (« même s'il commande de planter les choux la tête en bas, il faudrait lui obéir. » Mgr LeComte, évêque d'Amiens La Croix, 22 mars 1929).

Les évêques sont les serviteurs aveugles et dociles de Rome.

Si le Vatican leur avait commandé d'observer une réserve plus grande au lieu d'appuyer férocement les initiatives les plus chauvines et les plus réactionnaires, les évêques auraient bien été obligés de s'incliner.

Le contact ne fut jamais rompu entre le Pape et ses agents internationaux. Le cardinal Dubois, de Paris, le cardinal belge MERCIER, le cardinal allemand HARTMANN allaient librement à Rome pour s'entretenir avec leur Souverain Pontife et recevoir des mots d'ordre, tout en le mettant au courant de la situation militaire respective de chaque pays. Tous les gouvernements, par un favoritisme incompréhensible, toléraient les allées et venues des prélats et leur accordaient des facilités inouïes, même lorsqu'il s'agissait de traverser les pays dits « ennemis ». C'est qu'il fallait «maintenir le moral» à tout prix - et l'on comptait beaucoup sur le clergé pour y parvenir.

Nous ne pourrons jamais oublier que le clergé a joué un bien vilain rôle, au cours de ces tragiques années.

Les princes de l'Église allaient donc à Rome rendre visite au Prince de la Paix (?). Ils recevaient ses instructions. Mais, à peine rentrés chez eux, en Allemagne, en France, ou ailleurs, ils fulminaient contre les défaitistes, glorifiaient la beauté morale du combat, collabo-

12 BENOîT XV était d'ailleurs l'élu des Allemands, de même que son prédécesseur Pie avait été élu grâce à l'intervention du pieux François-Joseph.

« Un fait analogue se produisit lors du conclave de l'automne 1914, où les ministres de Prusse et de Bavière vinrent publiquement appuyer l'élection de BENOÎT XV. » (Le Crapouillot, Les Mystères de la Guerre, juin 1931). 
raient aux emprunts et à la récolte de l'or, bref, ils se faisaient les collaborateurs précieux de la guerre!

\section{De deux choses l'une :}

Ou bien le Pape leur avait donné des instructions pacifiques et ils lui désobéissaient (mais, dans ce cas, pourquoi ne les a-t-il jamais blâmés ni condamnés ?)

Ou bien le Pape leur donnait des mots d'ordre favorables à la « guerre à outrance » et ils les exécutaient (mais alors les discours pacifiques du Vatican constituaient une ignoble comédie !) ${ }^{13}$.

Je défie que l'on sorte de ce dilemme.

Lorsque le Pape eut commandé de faire des prières pour la Paix ${ }^{14}$, nos prélats tournèrent élégamment la difficulté. Ils firent des prières « pour la Paix par la Victoire », ce qui signifiait « pour la continuation de la guerre », tout le contraire de la Paix.

Le pape, ainsi bafoué, s'est-il jamais fâché contre les évêques ? Au contraire, il les accablait de bénédictions et d'encouragements.

Tous ces gens-là étaient d'accord pour saigner l'humanité à blanc.

13 «Les catholiques surtout étaient les plus haineux. Dans les églises, les curés, chaque dimanche, encourageaient à la tuerie. Rares étaient ceux qui se taisaient. Ils étaient presque tous abonnés à l'Action Française ou à l'Écho de Paris et puisaient dans leurs colonnes les enseignements d'un nouveau christianisme à la mode gallicane. Leur règne était revenu à la faveur de l'Union Sacrée. Reçus partout, appelés à collaborer avec les pouvoirs publics, ils ne pouvaient que bénir une guerre qui favorisait leurs desseins. A tu et à toi avec les généraux, ils s'étaient établis dans les états-majors et les apôtres du Christ ne rougissaient pas de côtoyer les servants de Mars. Dans de nombreux cantonnements, on obligeait les hommes à se rendre à la messe en colonnes par quatre. Ceux qui refusaient étaient punis ou privés de permissions... » (Charles FRAVAL, Histoire de l'arrière, p. 204-205.)

14 Encore une comédie ! Ces prières, répétées pendant quatre ans par des milliers de femmes et d'hommes, sont restées inefficaces, ce qui ne donne pas une grande idée de la bonté du Dieu chrétien, ni de l'efficacité des formules magiques enseignées par ses prêtres, de leurs bénédictions et de leurs cérémonies. 
Chacun des acteurs avait reçu son rôle à jouer et s'en acquittait à merveille.

Le pape prêchait «paix », les évêques répondaient «guerre ». et les fidèles applaudissaient tout le monde ${ }^{15}$.

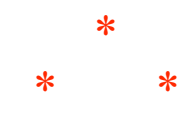

Derrière la façade de la «neutralité », la diplomatie vaticane ne restait d'ailleurs pas inactive. Elle travaillait et elle intriguait.

À moins de nier l'évidence, on doit admettre que les sympathies de l'Église, au début de la guerre surtout, allaient plutôt du côté des Empires centraux que du côté de l'Entente. J'ajoute que la chose était logique. D'abord, parce que le Vatican croyait à la victoire de l'Allemagne et qu'il escomptait un gros bénéfice personnel ${ }^{16}$. En-

15 On invoquera peut-être les services rendus par le Pape aux blessés, aux prisonniers, etc... C'est un argument d'ordre philanthropique qui n'a rien à voir avec le fond de la question. Le pape a fait du bien, c'est entendu : il a surtout soigné sa publicité !

Nous n'ignorons pas que la «charité », même sous les formes les plus sublimes, sert de paravent aux appétits ecclésiastiques et permet à l'Église de mettre plus facilement la main sur les consciences des malheureux qui sont réduits à faire appel à sa protection ou à son concours.

16 Il y croyait encore en 1917 ! Voici des déclarations catégoriques de BENOîT $\mathrm{XV}$ :

«Par son entourage, par une habile intervention des évêques allemands, BENOÎT XV croyait ferme que l'Allemagne serait victorieuse et qu'il fallait donc la ménager.

«Un archevêque français, celui d'Albi, pendant son séjour à Rome en 1917, avait exposé au pape lui-même la situation telle qu'il la voyait, lui exprimant sa foi entière dans le succès final de l'Entente, et BENOîT XV répondit textuellement :

- Les Français ont tort de tant parler de la victoire de la Marne, il n'y a pas eu de victoire à proprement parler ; ça n'a été qu'un mouvement de repli de l'armée allemande. Quant aux batailles de l'Yser, de la Somme et de Verdun, elles ont été sans résultats pour les pays de l'Entente. Vous croyez à l'épuisement de l'Allemagne, c'est une grosse erreur! Mes renseignements particuliers me permettent d'affirmer que les forces de l'Empire allemand ne 
sont pas entamées; une seule chose est certaine, c'est que les pertes de l'Allemagne sont très lourdes, comme celles des autres belligérants. Mais avec sa natalité, elle sera vite en mesure de combler les vides. Il n'en sera pas de même pour la France. Quoi qu'il arrive, l'hégémonie du monde appartient à la race germanique. Soutenir le contraire, c'est du bluff... (sic). »

« Je dois cette communication à Mgr LACROIX, ancien évêque de Tarentaise (lettre particulière du 30 septembre 1917), Mgr LACROIX était un ami particulier de l'archevêque d'Albi, qui le fit appeler pour l'assister à ses derniers moments »- Jean BERNARD, Histoire générale et anecdotique de la guerre de 1914, chap. VIII.)

N'allez pas croire que la germanophilie de BENOÎT XV ait été un phénomène exceptionnel. Tous les papes semblent avoir eu de la sympathie pour l'Allemagne contemporaine (luthérienne pourtant), pour se venger de la France anticléricale et athée.

Ainsi LÉON XIII, le pape prétendu républicain, était dans les meilleurs termes avec le Kaiser GuILlaUME II. Il lui écrivait (voir les Mémoires $d u$ prince de BÜLOW, II, 174) :

«... Vos principes de gouvernement (ceux de l'empereur d'Allemagne), je les connais et les ratifie (c'est nous qui soulignons). Je vous ai suivi et observé pendant votre règne et ai reconnu avec joie que votre souveraineté repose sur un christianisme intégral. Vous avez pour vous guider des principes religieux si élevés que je ne puis qu'implorer la bénédiction du ciel sur vous, sur votre dynastie, sur l'empire d'Allemagne et la prononce sur vous. »

«... J'ai fait ce rêve que vous, Empereur d'Allemagne, aviez reçu de moi, le pape LÉON XIII, la mission de combattre les idées socialistes et athées et de ramener l'Europe au christianisme... Je suis entouré d'Allemands et je suis devenu presque un demi-Allemand. "

Et ce post-scriptum précieux : «Le Pape a aussi demandé à Sa Majesté où en était la construction de la flotte et lui a dit qu'il souhaitait vivement qu'elle devînt puissante pour la protection de la Paix et des intérêts de la civilisation allemande. "

Après cela, il se trouvera encore des nigauds pour vanter la «neutralité » et le « pacifisme » du Vatican!

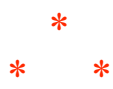

Mais il y a la contre-partie. Ce pape qui léchait les bottes à l'Allemagne secrètement — les léchait aussi à la France — non moins secrètement !

Dans son discours à la Chambre en faveur du rétablissement de l'Ambassade au Vatican, l'abbé LEMIRE affirmait que le Pape avait sauvé la France (! !) à plusieurs reprises, en particulier en 1875, en prévenant «secrètement» le gouvernement français des projets d'agression de l'Allemagne, et « en 1887, lors du redoutable incident SCHNCENEBELÉ, dont la 
suite, parce que la victoire française risquait de renforcer la République « athée et maçonnique » et le laïcisme que Merry del VAL détestait cordialement.

L'écrasement de la France, interprété comme une punition du ciel, pouvait permettre la restauration de la Monarchie et le rétablissement triomphal des privilèges ecclésiastiques.

Au début de la guerre, le Vatican, comptant sur une rapide victoire de l'Allemagne, ne prenait presque pas la peine de dissimuler sa germanophilie. " Nous sommes bien placés pour le savoir, en Suisse », écrivait le Journal de Genève (30 octobre 1918), qui rappelait les intrigues liées au temps où $\mathrm{M}$. de BÜLOW, résidant à Lucerne, avait des rapports suivis avec DisSENTIS et EINSIEDHN, à ZIZERS, près de Coire, résidence alors du Général des Jésuites. Celui-ci avait ses grandes entrées à la Cour de Vienne et par lui les « liaisons » étaient bien assurés entre la Curie Générale et ses amies d'Allemagne et d'AutricheHongrie (cité par M. CHARNY). Le P. LEDOCHOWSKI, général des Jésuites, était d'ailleurs un sujet autrichien (de Galicie).

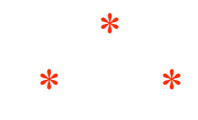

Il n'est pas indifférent de signaler le rôle joué par la monarchie espagnole — si cléricale ! — pendant la guerre de 1914.

solution heureuse pour la France fut due aux renseignements fournis par le pape LÉON XIII au président GRÉVY; de même entre les années 1914 à 1918. » (La Croix).

Le même LÉON XIII écrivait à l'empereur d'Allemagne pour lui donner sa bénédiction et lui dire son admiration, dans les termes obséquieux que j'ai reproduit plus haut. On avouera qu'il est difficile de jouer la comédie plus cyniquement.

L'abbé LEMIRE prétend que le pape trahissait et mouchardait l'Allemagne au profit de la France. Si le pape est capable de faire cela, il eût été aussi bien capable de trahir la France au profit de l'Allemagne ou de n'importe quel autre pays, s'il y avait eu intérêt.

Une telle politique est foncièrement immorale et constitue le plus redoutable danger pour la paix. 
Toutes les sympathies allaient à l'Allemagne.

Notre T.S.F. intercepta un jour le radio par lequel ALPHONSE XIII souhaitait à l'Empereur FranÇOIS-JOSEPH, le plein succès de ses armes!

Dans toute l'Espagne des prières publiques furent ordonnées pour demander à Dieu... l'écrasement de la France impie !

Les sous-marins allemands venaient librement se ravitailler dans les ports espagnols. Toute la presse officielle était ardemment germanophile.

Aussi la chute d'AlPhONSE a-t-elle été déplorée par la presque unanimité des journaux allemands.

Il faut que toutes ces choses soient connues. On pourra alors juger à sa juste valeur le patriotisme des réactionnaires et des cléricaux français, qui son allés se prosterner aux pieds de l'Alphonse déchu de son trône, vil assassin de notre grand Ferrer...

Mais il y a mieux.

ALPHONSE XIII faisait de l'espionnage pour le compte des Empires centraux.

« Notre service de renseignements intercepta un beau jour des télégrammes dont il parvint à surprendre le chiffre, télégrammes adressés par AlPHONSE XIII à GuILlaume II.

«Ces télégrammes contenaient des résumés de tous les renseignements communiqués au Roi par notre attaché militaire.

« En langage vulgaire : nous avions la preuve qu'ALPHONSE XIII abusait de la confiance du représentant d'une nation avec laquelle il affectait d'entretenir des rapports de la plus franche cordialité, et espionnait tranquillement cette nation, au profit de son ennemie.

«M. Clemenceau, très ému par cette révélation, pria le général DENVIGNES de faire tenir au roi des renseignements faux, procédé classique quand on se trouve en présence d'un « «agent double » qu'il faut 
quand on se trouve en présence d'un « «agent double » qu'il faut brûler. Les renseignements faux parvinrent à Berlin comme les vrais.

« On comprend mieux dans ces conditions, que le général MORDACQ ait notifié à M. QUINONES de LÉON le «non possumus» hautain de notre président du Conseil. » (La République, 19-4-31).

Clemenceau, en effet, plus logique et plus courageusement que nos «nationalistes» actuels, refusa, en 1918, de recevoir l'espion allemand ALPHONSE XIII.

Contentons-nous de constater que cet ALPHONSE était dirigé de la façon la plus absolue par les Jésuites et qu'il était entièrement à la dévotion du Vatican. S'il a donc servi l'Allemagne, s'il a collaboré aux tentatives d'écrasement de la France républicaine, cette constatation ne peut que renforcer ma thèse et aggraver les responsabilités, déjà accablantes, qui pèsent sur la criminelle Église romaine - dont ALPHONSE XIII n'était certainement que l'agent.

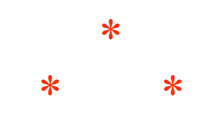

On invoquera certains efforts, certaines démarches parties de la Curie, en faveur de la Paix ? Des tentatives de paix séparée furent ébauchées par Rome, en effet, en 1917, entre l'Autriche et l'Entente. Faut-il voir dans ces tentatives la manifestation d'un sincère amour de la Paix ? Non! Le Vatican voulait simplement sauver l'Empire autrichien. Il savait que sa défaite militaire entraînerait inévitablement son démembrement, et c'est, effectivement, ce qui arriva. Or, l'Empire, je l'ai dit, était un des derniers remparts de l'Église dans le monde. Son gouvernement était le plus docile et le plus soumis à la Papauté. Là encore, le Vatican travaillait, non pour la Paix, mais pour lui-même ${ }^{17}$.

À ce moment, le président WILSON commençait son action pour la conclusion d'une "paix juste et durable ». Le Vatican, qui n'a pas renoncé à jouer le rôle lucratif et avantageux d'arbitre dans tous les conflits internationaux, voyait d'un mauvais œil cette activité se déve-

17 Voir plus haut la lettre du prince SCHONBURG. La sollicitude du pape pour la dévote Autriche y apparaît dans toute son ampleur... 
lopper. Aussi la presse catholique s'est-elle évertuée, pendant des années, à ridiculiser WILSON et ses «quatorze points ». M. Jean GUIRAUD, rédacteur en chef de La Croix, parlait avec mépris de cette " paix protestante ", voulue par WILSON. Ainsi, l'on n'aimait pas la Paix pour elle-même, au Vatican, mais on cherchait, comme toujours, à se servir d'elle comme d'un instrument de propagande catholique et de domination sur les États.

Si quelque lecteur doutait encore, non seulement de la sympathie qui régnait entre le Vatican et l'Autriche, mais de la complicité réelle et agissante qui les unissait en 1914, nous lui conseillons simplement d'ouvrir La Croix du 26 juillet 1914.

Six jours avant la déclaration de guerre, le grand journal catholique prenait catégoriquement position contre la Serbie.

En première page, dans un article intitulé : «Au pied du Mur » et signé R. T., on brossait le plus noir tableau de la situation de la France, rappelant l'anticléricalisme de COMBES «qui nous tue ». Et l'on concluait ainsi :

«Le moment est bien choisi, Messieurs, pour dire à l'Autriche qu'elle abuse. Prenez gare qu'en déchaînant la guerre par vos impostures et vos bravades, vous ne preniez le chemin qui mène les criminels d'État à la punition de leurs forfaits. Dans l'état de faiblesse insoupçonnée où vous avez réduit la France, EN PRESENCE DU BON DROIT EVIDENT DE L'AUTRICHE, vous n'avez qu'un parti à prendre : conseiller la modération à la Serbie, au lieu de l'exciter à la révolte. Vous risquez de nous entraîner dans sa chute. »

Lisez et relisez ce passage.

Relisez ensuite le télégramme du baron RITTER.

N'êtes-vous pas frappé de la similitude des deux argumentations?

Quelle confirmation éclatante de notre thèse! 
Comment douter ensuite que le Vatican ait poussé l'Autriche contre la Serbie, lorsque nous trouvons dans La Croix, à la même heure, une approbation aussi chaude de l'action autrichienne contre les Serbes? Les catholiques étaient alors beaucoup plus soucieux de travailler pour FRANÇOIS-JOSEPH que pour le maintien de la Paix en Europe ! 


\section{IX \\ LE RÔLE DE LA RUSSIE}

Cependant, la Paix pouvait encore être sauvée.

L'Autriche, conseillée par le Vatican, envoyait à la Serbie un ultimatum violent, volontairement inacceptable.

Si la Serbie avait accepté, malgré tout, cet ultimatum, le conflit était évité, ou tout au mois reculé...

Il fallait donc amener la Serbie à rejeter les propositions du gouvernement de Vienne, lequel immédiatement lancerait ses armées sur un voisin aussi remuant que dangereux.

Alors, la Russie intervint.

$\mathrm{Au}$ nom du panslavisme, on excite le gouvernement serbe et surtout — on lui promet l'appui du tsar et de ses formidables armées.

Mais, depuis de longues années, la politique française était faussée par tsarisme. Ce dernier multipliait ses efforts pour entraîner notre pays à seconder ses ambitions absurdes — sans négliger de lui souti- 
rer, sous forme d'emprunts, des sommes formidables (16 à 18 milliards de francs-or).

La presse française, fort vénale comme toujours, ne demandait pas mieux que de donner son concours. Elle fut copieusement arrosée. Il suffit de lire les documents (par exemple : l'abominable vénalité de la Presse) pour savoir que les dirigeants français ne dédaignaient pas, en complet accord avec ceux de Pétersbourg, d'intervenir auprès de la haute banque et de la grande presse... Ce fut notamment le cas de M. POINCARÉ, dont nous parlerons plus loin assez longuement ${ }^{18}$.

Donc, derrière les Serbes, la Russie.

Et derrière la Russie qui donc? La France.

Jamais le tsar n'aurait osé attaquer les Empires Centraux avec les seules forces russes, allant au devant d'un écrasement certain. La Russie n'a marché que parce qu'elle était assurée du concours de la France. Notre gouvernement a donc été, en dernier ressort, le véritable arbitre de la Paix.

Notre gouvernement aurait pu sauver la Paix, n'hésitons pas à le dire. Il lui suffit de déclarer à la Russie : « Notre traité d'Alliance est un traité défensif, et non pas offensif. Nous ne vous soutiendrons que si vous êtes attaqués, vous Russie... »

18 Simple échantillon, tiré des Archives russes :

Du 29 octobre 1914.

«Résumé de mes conversations avec PoINCARÉ et ambassadeur. Ils sont d'accord ajourner subvention presse, mais trouvent cependant désirable réserver crédit 300000 pour intervention subite s'il y a lieu dans avenir. Ceci est raisonnable et j'ai accepté ad referendum à Votre Excellence. Sur demande, POINCARÉ établirait demain avec LENOIR organisation éventuelle de ce service. PoINCARÉ me demande aussi recevoir PERCHOT et tâcher de la calmer, car sa campagne dans le parti radical devient gênante pour POINCARÉ et Alliance. $\gg-($ DAVIDOV.) 
Un tel langage eut rappelé l'entourage du tsar à la sagesse et la Serbie, plutôt que de faire «cavalier seul», aurait accordé à l'Autriche les satisfactions que celle-ci demandait.

Faire servir la France à une œuvre destinée à la briser, n'est-ce pas un chef-d'œuvre de machiavélisme?

Obliger notre grande République pacifiste à mettre elle-même le feu aux poudres, seuls les Jésuites pouvaient avoir assez d'audace pour imaginer cela!

Reconnaissons-le : ils ont manœuvré de main de maître.

Retraçons, très rapidement, les grandes étapes de leur abominable machination. 


\title{
$\mathrm{X}$ \\ POINCARÉ ET SON ACTION PERSONNELLE
}

\begin{abstract}
Nous sommes à un tournant de l'Histoire de l'Église universelle. Il s'agit de toutes les forces du mal de la Maçonnerie internationale contre l'Église; et dans cette lutte, la France se trouve au premier rang. Ce qui se fera en France servira d'exemple à tous.
\end{abstract}

Cardinal Merry Del VAL.

Parler du rôle joué par la France en 1914, cela équivaut à parler surtout de POINCARÉ.

Je ne veux pas refaire, après tant d'autres, le procès de cet ambitieux, mégalomane au cœur sec. Tous les esprits libres et studieux sont fixés à son sujet.

PoINCARÉ est le type de politicien sans idéal, qui s'est servi de la République, mais qui n'a jamais été sincèrement démocrate.

Pour réaliser son rêve orgueilleux, pour gouverner, il était capable de tout. 
C'est la droite, c'est-à-dire l'Église, qui a fait élire ce faux républicain à la présidence de la République ${ }^{19}$. Avant même d'arriver à l'Élysée il était déjà le prisonnier des cléricaux ! Marié civilement, il consentit, pour obtenir les voix réactionnaires, à faire bénir son union par l'Église. Il promit d'étrangler les lois laïques et la Séparation (voir documents du procès CAILlaUX). Promit-il également de seconder et d'appuyer la politique de guerre du Vatican? Ce sont les faits qui vont répondre.

Il n'est pas douteux que le retour des Congrégations, le rétablissement de l'Ambassade auprès du Vatican, etc., n'aient été imposés dès 1912 à POINCARÉ par l'Église, en échange de son appui :

«En 1912, le comte de Mun..., qui appartenait au GÉSU, annonçait alors, chez la vieille Égérie de la revanche, Mme ADAM, à Gif, qu'il fallait une bonne guerre pour régénérer la France ! (Cité par Gustave Dupin, M. PoINCARÉ et la guerre. L'auteur ajoute que M. de MuN fut l'entremetteur du pacte conclu entre Poincaré et les cléricaux. Peu après l'élection de PoINCARÉ, M. de Mun commençait dans l'Écho de Paris une campagne excitatrice, sous le titre L'Heure décisive).

Voici d'ailleurs un extrait de la prose du comte de MuN : «C'est pourquoi les bons français, pour qui je parle, se tournant vers lui (POINCARÉ), émus d'inquiétude et d'espoir : «Vous avez le pouvoir d'orienter la vie nationale, lui disent-ils, la Constitution vous le donne. C'est vous qui choisissez l'homme chargé de gouverner en votre nom. C'est vous qui pouvez, dans le Conseil, exercer sur les délibérations une influence décisive... La France est debout, prête au sacrifice, non pas résignée à l'immolation. Elle veut que, demain, quand sonnera l'heure, son armée soit puissante...» (Albert de Mun, Écho de Paris, 18 janvier 1913).

Ce dangereux belliciste — de MUN — est considéré comme un maître par les « catholiques sociaux »! ! Il était utile de le présenter sous sa véritable et malfaisante figure.

19 Aussi, le soir même de son élection, quelle joie chez les réactionnaires, qui organisèrent aussitôt de bruyantes manifestations à Paris, Nancy, etc... 
Il n'est pas inutile non plus de rappeler que ce fut le même M. de Mun qui osa exiger du ministre de la Guerre (général BILlOT), pendant l'affaire DREYFUS, des poursuites contre le courageux ZOLA, pour avoir écrit son admirable lettre : «J'accuse ! », qui déclencha le mouvement en faveur de l'innocent israélite que l'État-Major et les Jésuites voulaient maintenir au bagne.

Après la guerre, POINCARÉ continuera à obéir aux suggestions vaticanes. C'est lui qui fit restituer — illégalement — aux Jésuites, les propriétés qui leur avaient été confisquées. C'est également lui qui manigança le mauvais coup des fameux articles 70 et 71 .

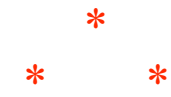

POINCARÉ arrive à la présidence. Immédiatement, il fait à la presse des déclarations imprégnées d'un chauvinisme provocateur. À partir de ce moment, par tous les moyens, on va préparer l'opinion, en excitant à toute occasion les instincts populaires contre l'Allemagne. On fait campagne pour le rétablissement du service de trois ans, on réorganise dans Paris de bruyantes «retraites» militaires, etc., etc.

Pour juger cette œuvre malsaine, appuyons-nous sur des documents qui, certes, ne sont pas inédits, mais sur lesquels on n'attirera jamais trop l'attention du public. Je veux parler des documents diplomatiques belges - antérieurs à la guerre et qui par conséquent sont tout à fait irréfutables.

Le baron Guillaume, ambassadeur de Belgique à Paris, écrivait dès le 14 février 1913, en parlant de POINCARÉ :

«...Cette popularité est faite de divers éléments; son élection avait été habilement préparées (Par qui, sinon les Jésuites!). On lui sait gré d'avoir, au cours de son ministère, manœuvré assez adroitement pour mettre la France en évidence dans le concert européen (Il n'a rien mis du tout en évidence et cette popularité se réduit à des campagnes de presse suscitées et payées par le Parti Noir, dès qu'il se fut assuré la complicité de POINCARÉ). Il a eu quelques mots heureux 
(inventés ou exploités par ladite presse) et qui ont fait impression. Mais il faut y voir tout d'abord une manifestation de ce vieux chauvinisme français, qui s'était éclipsé depuis de longues années, mais a repris avec force depuis les incident d'Agadir.

«M. PoINCARÉ est lorrain et ne manque aucune occasion de le rappeler; il fut le collaborateur et l'instigateur de la politique militariste de M. MiLlerAND; le premier mot enfin qu'il ait prononcé au moment même où il apprit son élection à la présidence de la république, fut la promesse de veiller au maintien de tous les éléments de la défense nationale. »

Le premier souci de POINCARÉ - et des Jésuites dont il était l'élu et l'instrument - fut donc de travailler au réveil du chauvinisme et du militarisme.

Dans une autre lettre, datée du 3 mars 1913, le baron GuiLlaume constate que le sentiment public français « devient chaque jour plus défiant et plus chauvin. »

«On ne rencontre que des gens qui vous assurent qu'une guerre prochaine avec l'Allemagne est certaine, fatale. On le regrette, mais on s'y résout. On demande le vote immédiatement et presque d'acclamation de toute mesure capable d'accroître la puissance défensive de la France. Les plus raisonnables soutiennent qu'il faut s'armer jusqu'aux dents pour effrayer l'adversaire et empêcher la guerre. »

N'oublions pas que cet aveu provient d'un homme d'État belge! Dans un rapport daté du 12 juin de la même année (1913), il dit encore :

«Les charges de la nouvelle loi seront tellement lourdes pour la population, les dépenses qu'elle entraînera seront tellement exorbitantes, que le pays protestera bientôt et la France sera devant ce dilemme : une abdication qu'elle ne pourra plus souffrir ou la guerre à brève échéance. La responsabilité de ceux qui ont entraîné la nation dans cette situation sera lourde... 
« La propagande en faveur de la loi de trois ans, destinée à amener un réveil du chauvinisme a été admirablement bien préparée et menée (Par qui ?). Elle a commencé par servir à l'élection de M. POINCARÉ à la Présidence de la République; elle poursuit aujourd'hui son œuvre sans souci des dangers qu'elle fait naître ; le malaise est grand dans le pays. »

Etes-vous convaincus maintenant? Suivez-vous la trame du complot et commencez-vous à apercevoir la main de ceux qui l'ont ourdi ? Combien de documents de ce genre pourrions-nous apporter!

Dans une correspondances ultérieure (10 mars 1914), le baron GuILlaume fait encore allusion à la louche politique de POINCARÉ :

«...Il est allé à Pétersbourg comme président du Conseil, il y retournera dans quelques mois comme président de la République.

« Il y a envoyé récemment M. DELCASSÉ, auquel il avait confié la mission de chercher, par tous les moyens, à exalter les bienfaits de l'alliance franco-russe et amener le grand empire à accentuer ses préparatifs militaires. »

POINCARÉ a donc suivi scrupuleusement la politique qui lui avait été imposée par les agents du Pape. Il est allé à Pétersbourg pour s'entendre avec l'odieux RoMANOFF. Et la tempête, savamment déclenchée dans les Balkans, n'a pas tardé à éclater. La catholique Autriche poussée par le Vatican, d'une part; le panslavisme déchaîné et excité, d'autre part, par Poincaré et les autres complices des Jésuites français (dirigés par Rome eux aussi). N'avons-nous pas devant nous, d'ores et déjà, les principaux facteurs du grand crime ?

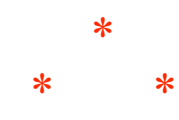

C'est surtout dans ses relations avec le gouvernement du tsar que la politique de POINCARÉ fut malfaisante.

Les documents RAFFALOVITCH, publiés par l'Humanité, montrent POINCARÉ collaborant à la corruption de presse, en 1912, avec Is- 
VOLSKY, HoKotzer et autres DAVIDOv. Des centaines de milliers de francs ont été répartis entre la plupart des journaux pour soutenir la propagande belliqueuse et revancharde incarnée par POINCARÉ.

Lorsqu'il est élu président de la République, il va jusqu'à promettre à l'ignoble ISVOLSKY que, même à l'Élysée, « il aura pleine possibilité d'influer directement sur la politique extérieure de la France ». Aujourd'hui, il ne craint pas de prétendre qu'il n'est jamais sorti de son rôle constitutionnel de pure neutralité...

Nous allons passer en revue quelques actes de sa vie politique, ministérielle ou présidentielle.

D'abord il rappelle l'ambassadeur à Pétersboug, Georges LouIs, qui ne se prêtait pas à sa politique et il le remplace par DelCASSÉ, qui était asservi à la politique anglaise et qui voulait la guerre avec l'Allemagne.

Dès 1912, POINCARÉ déclare que « si le conflit austro-serbe aboutissait à la guerre générale, la Russie pouvait compter entièrement sur l'appui armé de la France. »

C'est l'idée dominante de PoINCARÉ, plusieurs fois affirmée par lui : «Si la Russie fait la guerre, la France la fera aussi. »

Seulement, il craint que le peuple français — et même le Parlement, si facile qu'il soit à tromper et à corrompre - ne veuille pas entrer dans cette voie. Sa tactique sera donc la suivante (lettre d'ISVOLSKY à SAZONOFF) : il faut que ce soit l'Allemagne qui déclare la guerre à la France la première.

Dans le cas contraire, il aurait fallu un vote du Parlement. Une discussion publique eût été nécessaire et les plans du sinistre POINCARÉ risquaient d'être déjoués... Il fallait donc à tout prix placer le Parlement devant le fait accompli et obliger l'Allemagne à attaquer la première. C'est exactement ce qu'on a fait.

La Russie a mobilisé la première. 
L'Allemagne a riposté et, en mobilisant à son tour, elle demanda des explications à la France, qui refusa d'en fournir.

C'était la guerre, inévitablement.

Dès le mois de juillet 1922, la Société d'études documentaires et critique sur la guerre, avait publié (bulletin $n^{\circ} 2$ ) des documents qui éclairaient cette grande questions des responsabilités du grand cataclysme.

Puisons quelques faits parmi les plus probants :

Une dépêche ( $\mathrm{n}^{\circ}$ 102) de M. PALÉOLOGUE, ambassadeur de France, à Pétrograd, publiée au Livre Jaune Français, contenait cette phrase accusatrice : «Le gouvernement russe a décidé de procéder secrètement aux premières mesures de mobilisation générale. " Dépêche du 30 juillet au soir. OR, CETTE PHRASE A ETE SUPPRIMEE.

Un autre télégramme, expédié de Paris celui-ci, par IsvOLSKY, et publiée par le gouvernement soviétique dans un recueil de «Matériaux pour l'histoire des relations franco-russes de 1910 à $1914 »$, est tout aussi formel. En voici un extrait :

«Le ministre de la Guerre, de son côté, développant le même thème, a dit au comte IGNATIEFF que nous pourrions déclarer, dans l'intérêt supérieur de la paix, que nous consentons, à ralentir temporairement nos mesures de mobilisation, ce qui ne nous empêcherait pas de continuer et même de RENFORCER NOS PREPARATIFS MILITAIRES, en nous abstenant autant que possible de transport en masse de troupes. À 9 h. 1/2, il va y avoir sous la présidence POINCARÉ, un Conseil des ministres, à l'issue duquel je verrai aussitôt VIVIANI - IsVOLSKY »

Le gouvernement français était donc pleinement d'accord avec les ministres du tsar et ne désapprouvait d'aucune façon cette mobilisation. 
La France n'avait du reste jamais essayé de retenir la Russie sur la pente de la guerre. Poincaré et consorts semblent au contraire avoir appuyé la politique de provocation de NiCOLAS II et de ses généraux.

Un témoignage de PALÉOlogue est ici encore à noter :

«Relation de M. PalÉologue, ambassadeur de France : « La physionomie de M. POINCARÉ, comparée surtout à celle de son impérial hôte, est si intelligence, si vive, si décidée, qu'il en impose à tout le monde. Enfin, on s'est vite aperçu que l'empereur l'écoute avec une attention sérieuse, une attention DOCILE. »

Cette relation concerne le séjour de M. POINCARÉ à Pétersbourg, quelques jours après le drame de Seravejo, qui devait servir de prétexte au déclenchement de la tuerie.

On voit que POINCARÉ est au premier plan. Il parle haut et net; il «s'impose à tout le monde ». Le Tsar NicOLAS II, ce pauvre alcoolique, dégénéré et aboulique, l'écoute avec une « attention docile ».

Si POINCARÉ avait donc voulu servir la cause de la paix, il pouvait le faire avec succès. On l'aurait écouté. Par son attitude belliqueuse, par ses discours tranchants, par ses promesses de fidélité absolue aux traités d'alliance, il travailla au contraire pour la guerre.

Par la suite, pour dégager sa responsabilité, M. POINCARÉ a osé affirmer qu'il n'était pas sorti de son rôle «constitutionnel » et que c'était M. ViVIANI, président du Conseil, qui gouvernait effectivement. VIVIANI soutint cette thèse, mais il l'avait contredite lui-même auparavant, ainsi que le prouve l'extrait suivant du Bulletin précité :

«M. René ViViani a tout d'abord parlé du rôle constitutionnel de M. POINCARÉ. D'après lui, le Chef de l'État, « enfermé dans une constitution trop étroite », ne pouvait «agir». C'est donc M. VIVIANI qui aurait « agi ». Et il revendique la responsabilité de toutes les dispositions prises dans ces jours et dans ces nuits tragiques qui ont immédiatement précédé la guerre. Mais, par une véritable contradiction, M. Viviani prouve aussitôt que le vrai chef était M. Raymond POINCARÉ. M. Raymond POINCARÉ, ditil, « d'un regard perspicace, lisait toutes les dépêches émanant des ministères ». Et c'est ainsi que M. Raymond POINCARÉ est amené le 30 juillet 
« à dix heures » du soir, à réparer une bévue de son ministre de la guerre, M. Messimy, qui en ordonnant aux troupes le fameux retrait de dix kilomètres en arrière de la frontière - retrait qui semble n'avoir jamais été exécuté - avait tout simplement oublié d'en aviser «la cavalerie ». Un rien, comme on voit!»

Bref, POINCARÉ avait l'œil à tout et dirigeait tout. Il jouait le rôle pour lequel les cléricaux l'avaient placé à la Présidence de la République. M. COlRAT, ami personnel de M. Raymond PoInCARÉ, a pu dire que celui-ci avait suivi sa politique avec une adroite persévérance (textuel).

« Celui qui s'occupera un jour à dévoiler les dessous de l'histoire du commencement de la guerre devra apporter une attention particulière sur les journées que M. Raymond POINCARÉ passa à Pétersbourg, ainsi que sur celles qui suivirent ce séjour, environ du 24 au 28 juillet. Je suis fermement convaincu qu'en ce temps a été la décision de la guerre ou de la paix et le grand duc Nicolas Nicolaïevitch, SAZONOFF et M. Raymond PoINCARÉ se sont concertés pour paralyser coûte que coûte toute tentative pacifique... »- (V. SoukHOMLinov, ancien ministre de la Guerre de Russie : Mémoires).

Le Mercure de France (15-10-24) qui cite un long passage desdits « Mémoires », fait remarquer que SoukHOMLINOV était francophobe. C'est possible. S'ensuit-il que son témoignage soit à repousser d'une façon formelle? SOUKHOMLINOV était ministre au moment tragique de la mobilisation ; il était bien placé pour voir et juger des responsabilités. On peut n'admettre ses dires que sous toutes réserves et ne les accepter que dans la mesure où ils sont confirmés par les faits. Je laisse au lecteur le soin de juger s'il en est vraiment ainsi et si l'affirmation de SouKHOMLinov ne constitue pas une preuve nouvelle de la culpabilité du tsarisme et de POINCARÉ.

« Il faut que SAzONOF soit ferme et que nous le soutenions », dit-il à PALÉOLOGUE (21 juillet).

Ce dernier s'extasie devant la combativité poincariste ! "Voilà comment devrait parler un autocrate ! » constate-t-il dans ses Mémoires. 
Un autocrate peut-être, mais un chef d'État républicain, soucieux d'éviter à sa patrie une aventure effroyable et sanglante...

Débarquant à Dunkerque, le 29 juillet, à son retour de Russie, POINCARÉ dit au sénateur TRYSTRAM : «Ce serait grand dommage [que la guerre soit évitée]. Jamais nous ne retrouverions conditions meilleures...»

La responsabilité de la guerre incombe uniquement à POINCARÉ (et au parti clérical) - et non aux politiciens insignifiant et naïfs qui l'entouraient et qu'il a facilement manœuvrés, avec ses compères. C'est M. Isvolsky lui-même qui le proclame: "Tandis que $\mathrm{M}$. COMBES et ses amis clament partout, dans les couloirs parlementaires, qu'à la minute décisive la paix ou la guerre dépendra, non du Gouvernement, mais d'eux, en réalité, si, à Dieu ne plaise, la crise surgit, la décision sera prise par les trois fortes personnalités qui sont à la tête du cabinet : Poincaré, Millerand et Delcassé, et notre chance est que nous aurons affaire précisément à ces personnages et non à tels ou tels de ces politiciens d'occasion, qui se succèdent au cours de ces dernières années au gouvernement de la France. " (Cité par Ernest RENAULD, Histoire populaire de la guerre, t. II, p. 58.)

Plus tard, en 1920, écrivant un article dans L'Université de Paris, il fera cet aveu épouvantable :

«Dans mes années d'école, ma pensée, assombrie par la défaite, traversait sans cesse la frontière que nous avait imposé le traité de Francfort et quand je descendais de mes nuages métaphysiques, je ne voyais pas à ma génération d'autre raison de vivre que l'espoir de recouvrer nos provinces perdues...»

Elles ont été recouvrées, les provinces perdues — et c'est encore un succès pour la société cléricale. Le maintien du Concordat en Alsace, le mouvement autonomiste, n'ont-ils pas pour but de miner chaque jour davantage et de détruite les institution laïques afin de remettre la France sous le joug de l'obscurantisme? 
Admirons l'ingéniosité de nos adversaires, qui trouvent toujours le moyen de faire servir les événements, quels qu'ils soient, mauvais ou bons, au succès de leurs entreprises de domination sociale !

Je ne veux pas davantage insister sur POINCARÉ. C'est tout un volume qu'il faudrait écrire, pour réunir et commenter les innombrable et accablantes pièces de son dossier... ${ }^{20}$

J'estime que la présente démonstration est suffisante pour établir que Poincaré, élu président de la République par les cléricaux, instrument de l'Église et des Jésuites, a travaillé en faveur de la guerre et qu'il est responsable, dans une très grande mesure, de l'attitude de la Russie et de la Serbie au début de la conflagration mondiale.

20 Non seulement POINCARÉ doit être considéré comme un des principaux responsables de la guerre, mais il a été parmi les jusqu'auboutistes les plus acharnés. Après quatre années de massacres, sa folie guerrière n'était pas encore apaisée. Dans son livre: Grandeurs et misères d'une victoire, M. CLEMENCEAU écrit : «Ce même 8 octobre, M. POINCARÉ m'informe encore que « tout le monde espère fermement qu'on ne coupera pas les jarrets de nos troupes par un armistice si court qu'il soit. » (p. 92).

Voilà l'homme que les cléricaux encensent, alors qu'ils ont vilipendé des républicains comme ROUVIER et CAILLAUX, lesquels, à deux reprises, évitèrent la guerre à la France, ou des socialistes comme JAURÈS, qu'ils ont fait assassiner parce qu'il ne voulait pas trahir la cause de la Paix ! 


\section{XI \\ L’ASSASSINAT DE JAURÈS}

$\underline{\text { Retour à la table des matières }}$

Comment ne pas parler de cet épouvantable crime ? ${ }^{21}$

Je ne saurais le passer sous silence, en raison d'abord de la puissante personnalité du tribun socialiste, en raison surtout des conséquences produites par sa disparition.

La mort de JAURÈS a une signification, car JAURÈS était à la tête du mouvement d'opposition à la guerre.

L'avant-veille de son assassinat, il était à Bruxelles et il faisait décider par le Bureau socialiste international l'organisation d'un grand Congrès International, qui aurait lieu à Paris le 9 août et qui se dresserait devant la criminelle volonté des bellicistes.

Déjà, le 7 juillet, JAURÈS avait voté contre les crédits demandés pour le voyage de PoINCARÉ en Russie.

21 JAURÈS a été assassiné le 31 juillet, jour de la fête de saint Ignace de LOYOLA

— quelle coïncidence! 
Dans son journal l'Humanité, il multipliait les articles. Chaque jour, il intervenait auprès du gouvernement. Toute son activité, toute sa clairvoyance étaient tendues, arcboutées pour barrer la route à l'Horrible...

Un tel homme était gênant pour les amis de la guerre. Il fallait s'en débarrasser. Mais qui l'a fait tuer?

Certains ont insinué que c'était l'Allemagne, tellement son désir était grand de précipiter les choses. Personne ne prend au sérieux une semblable fantaisie.

D'autres accusent IsWOLSKY, l'agent du tsarisme et cette thèse est, assurément, beaucoup plus plausible que la première.

Mais on n'a pu établir l'existence d'aucun relation entre les milieux russes et l'assassin et JAURÈs, le sinistre VILLAIN.

Par contre, au lendemain de l'assassinat, on apprenait que le dit Villain était membre du Sillon de Marc SANGNIER. C'est le propre père de VILLAIN qui en fit la confidence à un rédacteur du Matin. Le Sillon n'était pas considéré, en effet, comme une entreprise de violence, mais comme un mouvement démocratique et libéral.

Les apparences évangéliques du Sillon n'empêchaient pas ce groupement d'être dirigé par les Jésuites. Son chef, Marc SANGNIER, suivait d'ailleurs les retraites fermées de la Villa Manrèse, à Clamart, où il allait prendre les mots d'ordre des Révérends Pères. (On peut d'ailleurs observer que les Jésuites contrôlent d'une façon toute spéciale le mouvement catholique « de gauche ». Ainsi les Jeunesses Ouvrières Chrétiennes, les Syndicats catholiques, les Semaines sociales, etc., etc., sont dirigés par eux.)

Bien entendu, La Croix repousse toute responsabilité dans le meurtre d'un homme qu'elle a pourtant toujours sali. Et pour mieux détourner les soupçons... elle accuse... l'Action Française !

«Ils n'avaient pas le droit - écrivait un rédacteur en chef du journal catholique - de se faire juges eux-mêmes, et encore moins de 
DÉLÉGUER à un pauvre malheureux, affolé par leurs articles, l'exécution d'une sentence qu'ils n'avaient pas LE COURAGE d'exécuter eux-mêmes. » (1-4-19)

Ce n'est pas moi qui plaiderai la cause de MAURRAS et de DAUDET, ni celle d'Urbain GOHIER et des autres calomniateurs de JAURÈS. Tous ces gens-là ont contribué, par leurs excitations criminelles, à créer l'atmosphère malsaine - au sein de laquelle le cerveau du pauvre malheureux catholique VILLAIN a pu subir la suggestion du meurtre.

Qu'il se soit excité tout seul, ou qu'on l'ait fanatisé, comme RAVAILLAC et tant d'autres, le résultat fut, hélas le même.

La Croix avait d'ailleurs attendu bien longtemps pour accuser 1'Action Française, qui fut durant des années son associée et sa collaboratrice dans l'action anti-républicaine et anti-laïque.

Je n'accuse pas le Sillon d'avoir organisé froidement l'assassinat de JAURÈS. J'ignore comment les choses se sont passées, mais je constate que l'assassin de JAURÈS était membre de cette association foncièrement catholique et fidèlement soumise au pape.

Les faits sont là et il n'appartient à personne de les nier.

Le meurtre de Jaurès par un catholique militant ne vient-il pas appuyer la démonstration faite plus haut?

Est-ce que tout ne concorde pas?

...JAURÈS lui-même, quelques heures avant sa mort, s'apercevait que la guerre était imminente et désespérant de sauver la paix se serait écrié (c'est RENAUDEL qui rapporte ce propos) :- C'est un coup des Jésuites!

Méditez ce propos, dont la valeur est d'autant plus grande que JAURÈS n'était pas systématiquement anticlérical — au contraire. 


\section{LA FALSIFICATION DU CATÉCHISME}

Un autre fait, tout aussi significatif, c'est la transformation du Catéchisme catholique, quelques semaines avant la guerre.

Cela parait invraisemblable, impossible ? Pourtant ce fait, dévoilé par un écrivain aussi loyal et intègre que G. DuPIN (Ermenonville), a été publié par de nombreux propagandiste sans jamais être démenti.

Voici en quoi consiste cette falsification, d'après M. Robert CHARDON :

«Examinons le $5^{\mathrm{e}}$ commandement de Dieu.

« Voici deux catéchismes du diocèse de Paris. Ils ne sont pas identiques. L'un date de 1908 et l'autre du 2 juillet 1914. Nous allons les confronter...

« Nous voyons sur le catéchisme de 1908 (page 77), les commandements, (tels que Dieu les donna à Moïse sur le Mont Sinaï ». 
$\ll$ Le $5^{\mathrm{e}}$ dit :

« Tu ne tueras point. »

« C'est là un ordre formel, inexorable, impératif, n'admettant aucune retouche. Un peu plus bas, même page, voici ce même commandement, en vers français :

« Homicide point ne seras,

«De fait, ni volontairement. »

« J'insiste sur ces deux mots : « De fait. »

«Jusqu'ici, nous sommes d'accord. Mais voilà le hic! En prévision du futur égorgement de 1914, le catéchisme fut révisé et transformé.

C'est pourquoi l'édition du 2 juillet 1914 nous présent, page 63, le même commandement ainsi camouflé :

« Homicide point ne seras,

« Sans droit, ni volontairement. »

« Sans droit, tout le distinguo est là. Les commentaires qui suivent et épiloguent à ce sujet, plusieurs semaines avant la guerre, sont révélateurs, aujourd'hui, quant aux préparatifs moraux de ce conflit. »

Un simple changement de deux mots, c'est peu de chose... Mais cela suffit à transformer radicalement le sens de la phrase.

C'est reconnaître le droit de tuer : c'est réfuter par conséquent et renier la célèbre interdiction attribuée à Dieu (qui ne s'est jamais gêné pour exterminer les humains, lui non plus !) : Tu ne tueras point!

Admettons que ce changement ait été nécessaire à notre époque de militarisme et d'étatisme. Il n'en serait pas moins curieux, inouï, que la modification ait été faite précisément quinze jours avant la déclara- 
tion de guerre, c'est-à-dire au moment même où le monde entier avait les yeux tournés vers l'Autriche et la Serbie et se demandait avec angoisse si la guerre pouvait être évitée, une fois de plus.

Si nous parlions le langage religieux, nous pourrions dire qu'une telle coïncidence a été... miraculeuse !

M. Armand Charpentier (Les Responsabilités de M. PoInCARÉ) commente la falsification du catéchisme dans les termes suivants :

« L'abbé DesERs, curé de Saint-Vincent-de-Paul, reconnut dans $L a$ Croix du 24 janvier 1924 qu'il était l'auteur de cette nouvelle rédaction. Mais il est bien certain que ce vénérable prêtre ne s'arrogea pas de lui-même le droit de modifier le texte que Dieu a dicté à Moïse, voilà plus de deux millénaires. Ce fut Mgr AMETTE qui lui suggéra la variante. Or, si l'on veut bien observer que la dite variante avait pour objet de libérer les consciences des catholiques, et plus particulièrement celle des prêtres qui pourraient être appelés à commettre le péché d'homicide, on en arrive à conclure que l'archevêque de Paris, qui venait de bénir, quelques mois plus tôt, le mariage de M. POINCARÉ, avait été vraisemblablement documenté sur l'éventualité d'une guerre prochaine.»

Armand Charpentier montre clairement la complicité de PoINCARÉ avec l'archevêque de Paris et le Vatican, en la circonstance. Car on pense bien que l'archevêque ne se serait pas permis de tripatouiller le catéchisme sans le consentement de son supérieur infaillible, le Pape!

Dira-t-on que ceux qui ont transformé le Catéchisme ne pouvaient pas savoir que la guerre allait éclater?

Allons donc ! Ils étaient au contraire fort bien renseignés.

Le pape n'est-il pas «l'homme le mieux renseigné du monde »? (Aristide BRIAND) 
La Croix reconnaît du reste que PIE X attendait la guerre, qu'il la savait inévitable. Il aurait fait à plusieurs prélats des confidences douloureuses, affirmant que 1914 verrait certainement la guerre éclater.

Cela ne diminue pas sa responsabilité — loin de là.

Mais puisque l'Église était si bien renseignée, puisqu'elle attendait la guerre avec une certitude aussi sereine, cela explique peut-être que l'on ait fait une nouvelle édition du catéchisme, affirmant le droit, pour un parfait chrétien, de verser le sang de ses frères en humanité... 


\section{XIII \\ «LA GUERRE EST DIVINE »}

L'Église ne craint pas la guerre. Elle en vit. Elle l'exploite, comme elle exploite tous les facteurs de souffrance, tous les malheurs, toutes les calamités.

Une humanité trop heureuse échapperait au prêtre. Elle n'éprouverait pas le besoin d'une céleste protection. La religion est née de la peur, elle a grandi par les larmes et s'est fortifiée dans les douleurs les plus atroces.

La guerre est envoyée par Dieu (le « bon » Dieu !)

Joseph de MAISTRE l'a proclamé, NAPOLÉON aussi et il paraît, d'après La Croix, que FOCH pensait exactement de la même façon.

Le pieux journal ajoute :

« Dieu est donc dans la guerre, pour la conduire, d'une main que l'on ne voit pas toujours. 
« Il y est encore, pour s'en servir comme d'un remède, pour tirer le bien du mal. Est-il nécessaire de rappeler, aujourd'hui surtout, quelle incomparable leçon de lumière et d'énergie est la guerre, quelle école de sacrifice et d'oubli de soi ?...

« D’une manière générale, la guerre éclaire les esprits, elle renouvelle les âmes, elle guérit souvent les nations.

« Là encore, après le désordre, après le mal, après le châtiment, l'ordre revient.

« Voilà quelle est, bien mal évoquée, hélas ! la pensée centrale de Joseph de MAISTRE; voilà quelle est la vision de son génie : partout, dans la cité comme dans les âmes, dans la morale comme dans l'intelligence, dans la guerre comme dans la paix, l'ordre gouverne le monde et Dieu gouverne l'ordre. »-(Ch. BAUSSAN, La Croix, 8-3-1921).

Que pensez-vous de cet « ordre », dont le fonctionnement a nécessité l'égorgement de dix millions d'innocents?

Et que pensez-vous de la sagesse, de la bonté d'un Dieu qui organise froidement de pareilles hécatombes — et qui les regarde s'accomplir d'un œil insensible?

Ces chrétiens-là nous présentent une image vraiment écœurante de leur prétendue divinité !

On a reproché aux Allemands d'avoir chanté et glorifié la guerre. Nous pourrions citer des centaines de Français, éminents, qui en ont fait autant.

M. BAZIN, académicien très clérical, n'écrivait-il pas, le 7 mars 1915, que la guerre : «C'est la chanson de geste qui continue, c'est la croisade qui n'est pas finie ; c'est Dieu transparaissant à travers la France purifiée. »

Le général catholique CHERFILS écrivait dans Le Gaulois : «La guerre est d'essence divine », et le général REBILLOT, dans la cléricale Libre Parole: "Il est temps que vînt la guerre pour ressusciter en France le sens de l'idéal et du divin. » 
Bel idéal, n'est-ce pas, que celui dont nous cueillons les fruits de la mort, de ruine et de barbarie depuis seize ans !

C'est en novembre 1914, la revue des jésuites : Études, publiant les lignes suivantes d'Yves de la BRIÈRE : "L'effusion du sang par la guerre doit être comptée, de même que toutes les autres calamités qui affligent le genre humain parmi les conditions providentielles de notre épreuve morale sur la terre... C'est l'expiation rédemptrice de nos péchés secrets ou publics. »

Déjà Saint Augustin appelait la guerre « un juste châtiment, une expiation utile, une préparation providentielle. »

C'est Dieu qui tient le glaive et qui frappe !

Le cardinal ANDRIEU, de Bordeaux, l'a rappelé en termes solennels :

« N'a-t-il pas frappé, lorsque la France, après avoir applaudi VolTAIRE et les encyclopédistes, expia leurs blasphèmes contre le Christ, qu'ils appelaient l'infâme, dans les horreurs d'une révolution qualifiée à bon droit de satanique? »

ROBESPIERRE et MARAT étaient donc les envoyés de Dieu comme les obus et les gaz asphyxiants sont les instruments modernisés !

« N'a-t-il pas frappé, fulmine le cardinal, lorsque nos faiseurs de lois laïques lui eurent dit : «Va-t'en; nous ne voulons plus de la science de tes voies ", et que l'on vit se déchaîner sur la France, sur l'Europe et sur le monde, une guerre aux proportions gigantesques, et dont les atrocités montrent, dans une lumière saisissante, le châtiment réservé aux peuples qui ont la folie de vouloir s'organiser sans Dieu. »

Quelle abominable mentalité faut-il avoir pour exposer des idées aussi inhumaines!

Dieu aurait fait mourir des millions d'hommes pour se venger... de ceux qui ont voté les lois laïques ! 
Ce fut pour punir les auteurs de la Séparation des Églises et de l'État qu'il a rempli le monde de veuves et d'orphelins !

Ce n'est pas une opinion isolée, elle est foncièrement orthodoxe :

« Dieu ne se plaît pas aux stériles vengeances et c'est pour nous sauver qu'il nous flagelle.» - (Père Olivier : au lendemain de l'Incendie du Bazar de la Charité).

«Si la France subit les souffrances qu'elle endure, elle est justement châtiée de son impiété. »—(BougniÈre, évêque de Constantine, 1916).

«La France a commis un crime, le plus grand, celui de ne plus croire, de renier Dieu. Le Créateur le lui fait expier justement par l'invasion. »(Chanoine GAUdEAU, dans la chaire de Saint-Sulpice, en septembre 1914).

Le Pape BenOÎT XV lui-même, en des termes plus habiles, n'a-t-il pas soutenu la même thèse, lorsqu'il a dit, à l'ouverture du Consistoire de 1915 : «Dieu permet que les nations qui avaient placé toutes leurs pensées dans les choses de cette terre, se punissent les unes les autres par des carnages mutuels, du mépris et de la négligence avec lesquels elles L'ont traité. »

«La France avait besoin d'une punition sanglante.» - (Chanoine LAGARDÈRE).

« Je pense que ces événements sont fort heureux... il y a quarante ans que je les attends... La France se refait, et selon moi, elle ne pouvait pas se refaire autrement que par la guerre qui la purifie. » - (Déclaration de Mgr BaUdrillart, Petit Parisien du 16 août 1914).

«Tous, ils vont à la bataille comme à une fête. »- (Petit Parisien, lieutenant-colonel RousSET, 15 mai 1915). (Le lieutenant-colonel RousSET était le collaborateur de l'Ouest-Éclair catholique pendant la guerre).

«Encore quelques années, s'écrie le général ReBillot (Libre Parole catholique), c'était la fin de la France. La guerre seule pouvait nous sauver. Mais, malgré le réveil de la fierté nationale, le pacifisme quand même l'aurait conjurée. C'est alors que la Providence s'est manifestée en inspirant à l'empereur Guillaume de nous la faire. » 
Un célèbre théologien romain, le Père Charles MAIGNIEN va nous donner (dans La Vérité Française, avant la guerre) une théorie qui confirme pleinement toute la thèse du présent ouvrage :

« Il y a une France qui est pour le monde un sujet d'effroi et de scandale, sans culte, sans foi, sans amour, sans honneur, sans conscience. L'apostasie officielle de la France, le régicide, la perversion systématique des âmes sont des crimes qui ne peuvent être effacés que par le sang. L'enseignement des peuples a besoin de cette leçon... J'attends que la République, favorisée jusqu'ici d'une paix prolongée, ait subi l'épreuve d'une grande guerre. »

Le même abbé ajoutait :

«Ce qui décidera l'avenir du Catholicisme en France, c'est la guerre, la vraie guerre. De pareils conflits peuvent se résoudre autrement et ailleurs, mais en France, ils se décident par le sang. " («La Vérité Française », 22 avril 1905).

Un autre religieux «éminent», Dom BESSE, proclame dans l'Univers :

« Le jeu des lois de la guerre nous rend l'âme d'une nation qui se bat pour vivre. Il prescrit comme la première condition du salut le retour au principe d'autorité. C'est dans cette direction que la France peut rencontrer la mystique de la guerre et utiliser les forces extraordinaires qu'elle met à sa disposition...

« La bataille est un facteur de l'ordre. Quand nous voulons glorifier Dieu, nous l'appelons Dieu des batailles...

«Voilà pourquoi Dieu a rendu la bataille et la guerre inévitables, et voilà pourquoi le peuple qui ne sait pas les apprécier est voué à la disparition. »

Vieille théorie, puisque nous la trouvons déjà (quelques mois avant la guerre de 1870 - ô coïncidence !) sous la plume de Louis VEUILLOT, la gloire du journalisme catholique !

«Nous croyons que les ruines de la guerre sont moins difficilement réparées que les ruines de la paix. On a plutôt fait de rétablir un pont, de relever une maison, de replanter un verger que d'abattre un lupanar. Quant 
aux hommes, cela repousse tout seul, et la guerre tue moins d'âmes que la paix. Dans le Syllabus, il n'y a point d'article positif contre la guerre. C'est surtout la paix qui fait la guerre à Dieu. »-(L'Univers, 26-6-1869).

Tous ces textes montrent que l'Église a toujours mis son idéologie et sa puissance morale au service de la guerre et du militarisme.

J'allais oublier l'illustre - et ridicule -Maurice BARRÈS, l'homme du couvent de Sainte-Odile !

«Il éclate enfin, le jour espéré pendant quarante-quatre années... Nous tenons la Revanche! Le mot, pendant quarante-trois ans, répété, fatigué, quasi discrédité, que nous étions des fous de maintenir, que nous eussions été mille fois plus forts d'abandonner, il est devenu un fait. Revanche. C'est un mot tout neuf, tout rayonnant de vérité, de joie, de gloire. Revanche de l'Alsace, revanche de l'armée. Merci messieurs les officiers !... $\mathrm{Ah}$ ! revoyons-les avec une joyeuse horreur, les années maudites (celles de la paix), qui sont bien écoulées. Je ne rappelle pas les temps abjects pour le plaisir d'y salir ma plume, trop heureuse depuis vingt jours de peindre avec des couleurs d'or les premiers feux, l'aurore de notre reconnaissance...

« La France respire à pleins poumons l'atmosphère des grands jours religieux et nationaux.

«L'ignoble pacifisme qui nous livrait pieds et poings liés, comme des pourceaux en sac, n'empoisonnera jamais les fils généreux des héros de $1914 \ldots$ Jurons-nous qu'après la guerre nous continuerons de donner en France le premier pas aux vertus héroïques des âmes guerrières et religieuses $! \ldots »$

Elles sont propres les « vertus » magnifiées par ces répugnants héros de l'arrière ! Leurs déclamations n'avaient pas d'autre but que de servir la politique infâme de l'Église...

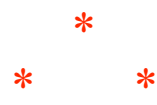

Dès que la guerre éclate, le chauvinisme s'accentue. Les journaux réactionnaires (et les autres aussi, hélas !) s'emplissent d'excitations, de mensonges, d'insultes. Le massacre est glorifié. On s'ingénie à sa- 
lir l'ennemi, à inventer les accusations les plus baroques - et tout cela pour que les malheureux soldats bernés participent au carnage avec une frénésie plus folle...

Les gens d'Église (au mépris de la morale chrétienne !) sont les plus haineux de tous :

«...Mais je gage que, lors de la ruée boche vers Amiens, nos artilleurs préféraient encore «taper dans le tas » avec nos élégants obus de 75 qui n'empoisonnent pas à la façon des vitrioleurs, mais anéantissent proprement des bataillons entiers. » - (Abbé Th. MoreuX, Petit Journal, 8 avril 1918).

«Il est certain que la barbarie allemande s'étale avec cynisme aux regards du monde. Jamais personne ne pourra voir un Allemand sans s'écrier : Voilà un monstre !... Il faut bien se mettre dans la tête qu'il y a des siècles et des siècles que nous avons affaire à une peuplade féroce et sauvage. L'Allemagne est au-dessous de la brute et doit être traitée comme telle. Nous réclamons des sanctions. Les Allemands doivent être traités comme des apaches, s'ils tombent entre nos mains. »-(La Croix, 13 janvier 1915).

Il est difficile de descendre plus bas dans la haine et la mauvaise foi. Nous pourrions citer des centaines d'articles de ce genre, puisés dans La Croix, L'Écho de Paris, etc. Et ces gens-là se disent chrétiens ! Et ces gens-là ont la prétention, aujourd'hui, d'être les meilleurs défenseurs de la paix ! Quels tartuffes !

Aujourd'hui, on s'aperçoit que ces doctrines portent tort à l'Église, dans nos pays démocratiques. On reconnaît qu'elles lui ont aliéné les sympathies populaires. Retenez cet aveu, que j'extrais de la $\mathrm{Vie} \mathrm{Ca}$ tholique (16 mars 1931) :

« Oui, depuis plus de quarante années, dans les masses populaires, tout catholique paraît nécessairement être chauvin, tout militariste un croyant. Il faut bien dire que nous avions tout fait pour compromettre la religion à la suite des Boulanger, des Déroulède, des CASSAgnaC, des Marcel Habert, des Maurras, des Daudet, des Buret ou des Coty. Sans nul discernement, au moment même de l'affaire DREYFUS, nous avons épousé toutes les passions antisémites d'un DRUMONT, comment s'étonner que nous récoltions, de leur héritage, toutes les colères qu'ils avaient soulevées? 
Les élections de 1932 se feront en grande partie pour ou contre une certaine politique de paix ; aussi, sans jouer les Cassandre, on peut prévoir que, si nous ne prenons point soin auparavant à dissiper cette périlleuse équivoque, les catholiques pourront payer très cher d'avoir boudé les directives de Rome. »

Voilà qui s'appelle montrer le bout de l'oreille... électorale !

Mais comment pourrions-nous croire à la sincérité du pacifisme de la Vie Catholique, lorsque nous lisons dans ce journal des éloges de Louis VEUILLOT, dont je viens de rappeler les doctrines bellicistes; de Louis VEuILLOT présenté comme le modèle du chrétien intègre ? (numéro du 11-4-31).

Théorie abominable, je le répète, mais qui a le grand avantage de nous découvrir la pensée secrète de l’Église.

Oui, elle voulait la guerre! Oui, elle l'appelait de tous ses vœux! Oui, elle l'a préparée et facilitée de son mieux !

Pour pouvoir dire ensuite : La France est punie de son impiété !

Pour obtenir l'abrogation des lois laïques, pour que les gens d'Église rentrassent en possession des privilèges abusifs qui leur avaient été retirés.

Le crime qu'il attribue à Dieu, c'est le Clergé qui l'a commis !

Et c'est le Clergé qui en a profité...

Écoutez l'abbé G. HÉNOCQUE :

«Qui donc ne se souvient des premiers jours de la grande guerre ! Nos églises ne désemplissaient pas ; tout le monde venait s'agenouiller pour demander à Dieu d'épargner les êtres chéris, qui allaient défendre le sol sacré de la Patrie... » 
Tout récemment, M. ZAMANSKI se félicitait dans La Croix (15-731) du chemin parcouru par l'Église depuis trente ans - grâce à la guerre !

« Tout de même, nous sommes loin de 1903. Trente ans bientôt! 1903, c'était Combes. Alors, on s'est bien battu. Dans la rue, dans les meetings, dans les églises, aux processions, jusqu'à l'effusion de sang. Rappelezvous les Fêtes-Dieu de année-là, encadrées de gourdins.

«Puis ce furent la Séparation et la loi de 1904. Et l'on continua de batailler ferme... jusqu'à la grande coupure de 1914, où ce fut une autre bataille.

« Du coup, nous reprenions des positions, etc..., etc...»

La grande pêcheuse en eau trouble le savait bien que les souffrances et les deuils lui ramèneraient la clientèle éperdue des faibles, des mystiques, des âmes désemparées...

Aussi, quel enthousiasme !

Pendant des années, prêtres et évêques exhorteront frénétiquement au massacre.

Plus la saignée sera prolongée, plus la France sera épuisée — et facile à remettre sous le joug.

Aussi, Mgr Tissier, évêque de Châlons, proclamait énergiquement : « Le triomphe, à n'en pas douter, coûtera encore bien du sang ! Mais chaque goutte qui tombe la lave davantage (la France) et la fait plus belle, chaque flot qui coule la pousse vers Dieu et resserre son union sacrée ; chaque rosée vermeille qui s'étend sur la plaine au matin et au soir des batailles y sème des hommes...

« Noble sang de France, épands-toi et ruisselle encore s'il le faut du corps de nos fils (?), car tu es notre rançon, la rançon de nos villes et de celle de nos champs! Inonde nos tranchées et nos côteaux! Tu seras la force invincible de la terre qui te boit et le vin parfumé de la Champagne n'est que le symbole de ta vertu. Rien ne t'épuise, sang 
chevaleresque de nos petits soldats... etc., etc. » (Sermon du 19-91915, à Notre-Dame d'Épernay).

Ce lyrisme alcoolique et sanglant peut-il être considéré comme un langage d'un « ministre de la paix »?

Est-ce de la folie ou du cynisme ? Jubiler ainsi devant les flots de sang répandus! Se délecter comme une hyène hystérique devant la rosée vermeille inondant les champs de bataille ! Fallait-il que la joie de retrouver leur prestige et leur pouvoir soit forte pour que les princes de l'Église en arrivent ainsi à perdre tout sentiment d'humanité et toute mesure!

«Et le soir, dans les tranchées, l'on chante la prière du soldat... sur l'air du Clairon de DÉROULÈDE », constate béatement, le chanoine GAUDEAU.

La religion d'amour et de pardon fut ainsi complètement militarisée.

M. SchetTER, aumônier de division dans l'armée allemande, écrit dans son ouvrage intitulé Au nom de Dieu - jusqu'au bout :

« On donne au soldat le fer froid, il doit s'en servir sans timidité ; il doit l'enfoncer dans les côtes de l'ennemi ; il doit briser son arme sur le crâne de l'adversaire. Tel est son devoir sacré, son service divin. »

Le père SERTILLANGES proclame à la Madeleine :

«Le 75 se tait. Le capitaine tire son revolver de l'étui. Tout le monde comprend. Suit un moment d'angoisse mortelle. « En avant!» Ah ! c'est la minute divine... » (Cité par l'Eil de Paris, 19-7-30)

Voilà ce qu'ils ont fait du Christianisme ! 


\section{XIV \\ L'ÉGLISE EST-ELLE DEVENUE PACIFISTE?}

Une évolution très politique (comme tout ce que fait l'Église) se dessine pourtant en France depuis quelques années.

Le Clergé prétend être le plus sincère ami de la paix.

La Papauté multiplie les manifestations anti-guerrières... verbales.

L'Action Française et son nationalisme fougueux (dont on s'accommodait fort bien autrefois) ont été bruyamment condamnés.

Pourquoi ce changement de tactique?

D'abord, parce que l'Église se serait discréditée en agissant autrement. Les peuples haïssent la guerre et l'Église désire se rendre sym- 
pathique aux peuples, afin d'endormir leurs légitimes méfiances, pour les assujettir à nouveau.

Ensuite, le Pape s'était imaginé qu'il entrerait à la Société des Nations et qu'il en deviendrait le président (peut-être n'y a-t-il pas complètement renoncé). Quel prestige pour le Vatican et quel triomphe pour la Sainte Église ! 22

Toutes ces comédies hypocrites rendent plus dangereuse encore la politique machiavélique des papes.

Ils continuent en effet à miser sur les deux tableaux.

Un jour, l'évêque de Mayence blâme le mouvement hitlérien, insuffisamment soumis à Rome ${ }^{23}$.

22 Le rétablissement du pouvoir temporel permettra-t-il au Pape de réaliser ce projet, à présent qu'il est devenu le chef d'un État souverain ? État microscopique, d'ailleurs : 44 hectares ! Pas même un demi-kilomètre carré... Et la Société des Nations a refusé d'admettre la République d'Andorre (452 kilomètres carrés), celle du Lichtenstein (150 kilomètres), celle de Saint-Marin (85 kilomètres). Alors?

23 Par contre, l'évêque de Berlin a bruyamment approuvé HiTLER. Et le Pape fut bien embarrassé... Car c'est dans la très catholique Bavière que le mouvement hitlérien recrute ses plus nombreux et ses plus ardents adeptes. S'il a fini par prendre position contre le mouvement hitlérien, ce n'est pas tant en raison de son caractère guerrier et revanchard de celui-ci, mais tout simplement parce que HITLER et ses amis entendaient se soustraire à la discipline du Vatican. Le Pape fait toujours passer ses intérêts avant toute autre considération. C'est ainsi qu'il vient de se réconcilier avec MusSOLINI...

Le Pape est tout prêt à s'entendre avec HitLER, comme avec Mussolini, dès que ses intérêts le lui commanderont. C'est ainsi que le chancelier BRÜNING : «Envoie à Rome son ami Mgr KAAS, pour négocier, sous l'égide du Vatican, l'entente de son parti, le centre catholique, avec HITLER. Bien mieux, cette entente, il l'applique déjà sur le terrain électoral, en Hesse, notamment, où elle vient de s'affirmer dans l'élection du président de la Diète. »(«Figaro » et «Écho de Paris », 16-12-31).

Un fait mérite d'être signalé. La propagande d'HITLER a été subventionnée par le Crédit Lyonnais, banque ultra-réactionnaire, présidée par le clérical baron de BRINCARD. Singulier patriotisme... et singulier christianisme ! (Voir Petit Bleu et Forces) 
Mais le pape recevant une délégation de jeunes Allemands prononça une allocution inquiétante. C'est le journal tardieusard L'Ordre, lui-même, qui l'a signalée :

« On pouvait croire que la victoire des hitlériens en Allemagne allait provoquer chez les orthodoxes pacifiques une violente réaction. Il n'en est rien. La plus haute autorité morale dans le monde, le pape PIE $\mathrm{XI}$, qui, on s'en souvient, condamna, il y a quelques années, la doctrine nationaliste de 1'Action Française, vient de déclarer à une délégation de la Jeunesse catholique allemande :

«Bénie soit cette jeunesse qui se rénove dans une Allemagne qui se rénove. »

PIE XI n'a pas donné seulement un encouragement aux forces catholiques, il a applaudi à l'ère nouvelle qui s'ouvre pour l'Allemagne. Le succès des hitlériens, il l'interprète comme l'indice de temps meilleurs. Est-ce que, par hasard, il approuverait chez nos voisins ce qu'il réprouve chez nous? » (Numéro du 25 septembre 1930).

Un autre jour, l'évêque de Gênes, le cardinal MinORETTI, bénit un nouveau croiseur de guerre et prononce un discours des plus chauvins (septembre 1930) ${ }^{24}$.

24 On fait la même chose en France. Le 2 septembre 1931, à Senlis, on a célébré l'anniversaire du massacre des habitants de cette ville, perpétré par les Allemands en 1914 (ces cérémonies odieuses n'ont pas d'autre but que d'entretenir les haines entre les peuples). On a célébré une messe à la cathédrale, en grande pompe. Les autorités y assistaient ! Et ensuite, au cimetière, M. LOUAT, maire de Senlis, a prononcé un discours révoltant de haine contre l'Allemagne. Dix-sept ans après la guerre, voilà où ils en sont, ces néfastes serviteurs de l'Église!

La récente enquête de l'Oeuvre (décembre 1931) sur l'enseignement actuellement donné dans les écoles confessionnelles, est véritablement significative.

D’une façon générale, dans ces écoles, l'éducation s'inspire d'un chauvinisme exaspéré. On y mange du boche et on y exalte les grandeurs (?) et le beautés (? !) du sacrifice guerrier.

Ceci n'est-il pas une preuve supplémentaire de l'hypocrisie cléricale ? Pourquoi l'Église se dit-elle pacifiste (jouant ainsi une comédie politicienne) 
On organise à Livourne une Légion Corse, contre la France. Un aumônier militaire, Luigi BASSO, bénit le drapeau et participe au défilé enthousiaste (La République, 31-8-30)

En France, c'est l'évêque d'Agen, M. SAgot du VAuroux, qui fulmine contre le pacifisme, pour lequel il n'éprouve pas « la moindre sympathie » et contre un " internationalisme abject parce que lâche et jouisseur » (! !) (cité par 1'Action Française, 2 juin) 25.

puisqu'elle s'applique, dans ses écoles, à fabriquer des générations chauvines, qui se laisseront docilement pousser, demain, sur les champs de bataille ?

25 Le même Mgr SAgot du VAuroux, évêque d'Agen, haranguant la jeunesse catholique, déclare :

« D’abord, préservez-vous, préservez autant que vous le pourrez vos amis des doctrines perverses insensées du pacifisme, de l'antimilitarisme, de l'internationalisme. Ne soyez point de ceux qui veulent à « tout prix » la suppression de la guerre. la justice et la charité, encore une fois, nous les appelons de tous nos vœux ; de nouveaux envahissements de notre territoire, des désastres comparables à ceux de 1870 et de 1914 , non, non, nous ne nous y résignerons jamais.

«Un second devoir, c'est le respect de nos gloires militaires. Quelle honte que de calomnier comme on l'ose les chefs de nos troupes, l'admirable corps de nos officiers, et jusqu'à ceux qui ont sauvé, au sens exact de ce mot, notre bien-aimée patrie, en remportant des victoires qui comptent parmi les plus belles de notre histoire !...

« Les vertus guerrières sont une tradition française, soyons-en fiers et gardons-en jalousement l'honneur, pourvu qu'elles ne s'exercent jamais que pour le défense de saintes causes.

« Votre troisième et dernier devoir a pour objet la franche acceptation du service militaire avec sa préparation et les périodes de manœuvres qui le complètent. On parle beaucoup de désarmement. Soit, mais à la condition qu'on le décrète universel et qu'on l'opère loyalement. Gardons-nous de devenir des dupes, ne mettons pas sottement notre gloire à tendre les bras aux hommes qui nous ouvriraient les leurs pour nous étouffer...

«Le meilleur moyen d'empêcher de nouvelles guerres, mes chers amis, sera longtemps encore d'inspirer à nos rivaux et à nos adversaires un sentiment de crainte révérencielle. Soyons forts par l'union de tous les bons Français et leur patriotisme; soyons forts par la pratique des vertus qu'exigent la grandeur et la prospérité nationales ; soyons forts par la solide organisation de nos armées et la puissance de nos ressources financières. L'esprit de paix ne s'oppose nullement aux sages précautions; il se développera d'autant mieux 
chez nous que l'état de notre pays manifestera plus de santé physique et de vigueur morale.» - («La Croix » 6 juin 1929).

Il est difficile d'aller plus loin dans la voie du chauvinisme !

Soyez assuré, mon cher lecteur, qua la quasi-unanimité des évêques sont aussi militaristes et guerriers que celui d'Agen.

En voici un autre exemple : "Après les archevêques de Berlin et de Londres, après Mgr Verdier et tant d'autres, Mgr de la ViLlerabel, archevêque de Rouen, a voulu apporter se petite contribution personnelle à la sanctification du massacre.

« Aux jeunes clercs de son diocèse qui participent à la dernière ordination, il a déclaré :

«Il se trouve parmi les catholiques quelques rêveurs qui vont de l'avant avec une générosité mêlée de trop d'illusions. Ils en arrivent à dire que les catholiques ne doivent pas porter les armes, même pour se défendre. Quelle aberration et contraire à l'enseignement de l'Église !

«Dieu, qui a suscité Jeanne d'ARC, nous a montré qu'il y a des guerres justes où tous doivent faire leur devoir avec courage »- («Monde » 2 janvier 1932).

« Le cardinal VERDIER a donné à 1' «Intransigeant» une interview qui lui a valu les chaudes félicitations de «l'Ami du Peuple» : "songeons que le cri d' « A bas la guerre » qui retentit si souvent chez nous, n'est jamais poussé à Berlin, et répétons avec le cardinal VERDIER dans l'interview qu'il vient de donner à un de nos confrères: "La sécurité doit être pour notre Gouvernement le premier des soucis. »

En Allemagne, c'est la même chose. On vient de frapper une revue bavaroise («Allgemeine Rundschau»), coupable d'avoir préconisé une étroite alliance de la Bavière et de la France. «La Croix » (10 février 1931) reproduit ce commentaire de la catholique « Germania » :

«L' "Allgemeine Rundschau» a maintes fois fait place, ces derniers temps, à des tendances qui n'étaient pas favorables au prestige et aux intérêts de l'Allemagne. La masse des catholiques allemands refusera avec énergie de faire siennes ces tendances de 1' "Allgemeine Rundschau » qui ont provoqué sa suspension. "

Dans le même numéro de «La Croix », Pierre L'ERMITE, rédacteur en chef du pieux journal, écrit : «Les Allemands ont brisé les murailles, incendié les maisons, pillé les villes. La seule chose qu'ils n'ont pas pu emporter, c'est la terre. »

Voilà comment les cléricaux travaillent à l'apaisement franco-allemand !

Le Pape lui-même, si prodigue ordinairement de belles et pacifiques paroles, a déclaré, à l'occasion de la nouvelle année, qu'il ne dirait rien en faveur de la Paix, étant donné que les peuples étaient restés sourds à ses précédents appels. Il s'adressera désormais directement à Dieu !! C'est moins compromettant, en effet — et tout aussi inefficace, hélas ! 
C'est l'abbé MACQUARD qui écrit dans le Bulletin du Diocèse de Reims : "Se livrer avec ses ennemis d'hier à des embrassades inconsidérées autour d'un arbre de la paix sur des ruines encore fumantes, est-ce vraiment faire œuvre de paix ? »

Ils jouent la comédie en se disant les amis de la Paix — alors qu'ils soutiennent les MARIN, les KERILLIS et toute la clique militaire et belliciste.

Partout où triomphe une politique de dictature et de réaction, une politique guerrière dirigée contre le peuple, par une coïncidence curieuse, l'Église est forte. Les nations les plus dangereuses pour la paix son également celles qui sont le plus entièrement inféodées au cléricalisme, à l'antisémitisme, etc. (Roumanie, Pologne, Hongrie, etc.).

À la tête de l'armée française, les Jésuites ont placé le général Weygand (« il est enfoncé dans les curés jusqu'au cou », disait CLEMENCEAU). Or ce général-capucin, tout récemment encore, a prononcé un discours des plus chauvins, rempli de méfiance à l'égard de l'Allemagne, à l'heure même où MM LAVAL et BRIAND allaient négocier à Berlin.

Enfin, on sait que récemment, l'archevêque de Paris, Mgr Verdier, a osé envoyer à M. CoTY, le forban belliciste de l'Ami du Peuple, une lettre qui est un chef-d'œuvre de platitude ! Ce journal traite les pacifistes de froussards et leur reproche d'éprouver un "désir morbide de paix $\gg ! ! 26$

Est-ce l'attitude d'un véritable et sincère ami de la Paix - qui devrait mettre celle-ci, s'il était vraiment «chrétien » (et humain !) AU-DESSUS DE TOUT !

26 Bien entendu, je juge tout à fait superflu de m'arrêter à l'argument dont on a tant usé et même abusé ; à savoir que les curés ont fait la guerre avec bravoure, qu'ils ont versé leur sang pour la patrie et la plupart d'entre eux ont accompli des prodiges de bravoure. Nous savons que la publicité cléricale est bien faite et nous tenons compte du bluff et de l'exagération devant lesquels nos adversaires ne reculent jamais, quand il s'agit de servir leur cause ! 
Albert BAYET a fort judicieusement répondu en publiant... des statistiques. les chiffres méritent d'être connus : Les gens d'Église ont été mobilisés au nombre de 32699 et ont perdu 4618 des leurs. ce qui fait un pourcentage de $14,1 \%$

Mais, pendant ce temps, les instituteurs laïques, si souvent insultés par la presse catholique, mobilisés au nombre de 35817 laissaient 8119 des leurs sur les champs de carnage, soit $22,6 \%$

Donc, les instituteurs laïques ont perdu $50 \%$ de plus des leurs, à la guerre, que les congréganistes et les curés. Vous verrez que ces chiffres ne seront pas reproduits dans... le Livre d'Or des religieux anciens combattants !

La France impie est, du reste, le seul pays qui ait mobilisé les gens d'Église. Rappelons que les papes n'ont jamais approuvé cette mesure démocratique et qu'ils continuent à réclamer pour leurs prêtres un traitement de faveur. Le cardinal BILLOT n'écrivait-il pas, en 1915: «Nous devons, au contraire, nous bien persuader que la loi qui assujettit le clergé à la milice est une loi impie, sacrilège, révolutionnaire et athée, en pleine opposition avec l'ordre établi par Dieu et attentatoire aux droits les plus sacrés de l'Église, aux immunités dont elle a joui jusqu'à ce jour chez tous les peuples et dans tous les temps. »-(Cité par Ernest JUDET).

Le cardinal ajoute que la mobilisation des curés est un outrage et un affront! (Qu'en diront les millions de pauvres bougres qui ont dû, la rage au cour, subir le même affront?)

En somme, les gens d'Église, voudraient bien envoyer les autres à la guerre, tout en restant à l'abri dans leurs temples pour empocher les gros sous des âmes broyées par la catastrophe... 


\section{XV \\ UN PLAIDOYER MALADROIT}

$\underline{\text { Retour à la table des matières }}$

Les responsabilités de l'Église sont tellement évidentes, tellement visibles, que ses représentants ne se fatiguent pas de plaider sa cause — avec une obstination maladroite et des arguments puérils. 27

Ainsi La Croix a entrepris, dans un long article de tête (12-9-30), de démontrer que la guerre n'était pas l'œuvre « des curés et des capitalistes » $($ sic $)$.

Grossière diversion !

27 Parmi ce plaidoyers, il faut surtout retenir les principaux : celui de Marc SANGNIER, le célèbre fondateur du Sillon (dont l'assassin de JAURÈS était membre), et celui, plus copieux, d'Ernest JUDET. Ancien directeur du Petit Journal et de l'Éclair, homme de confiance du Vatican, M. JUDET a joué dans l'affaire DREYFUS un rôle tristement célèbre. C'est lui qui osa, pour abattre Émile ZoLA, saisir la mémoire de son père, en inventant des faux. Pour ces calomnies et ces diffamations, il fut presque condamné. Tel est JUDET, le principal champion de la Papauté, choisi pour glorifier sa prétendue œuvre de paix ! 
Personne n'a jamais accusé les curés - mais l'Église, la Haute Église, la Curie Romaine, la Compagnie de Jésus. Ce n'est pas du tout la même chose!

En ce qui concerne les capitalistes, même observation. C'est la Haute Banque, la grosse métallurgie, les fabricants de canons qui ont poussé sournoisement à la tuerie - utilisant les services d'une presse stipendiée pour mentir au peuple et exciter le chauvinisme.

Dans un monde où s'épanouissent l'Église, le Capitalisme, le militarisme et la Diplomatie secrète, la guerre n'est-elle pas fatale ?

Le rédacteur de La Croix s'applique à démontrer que les curés n'ont pas profité individuellement de la guerre et qu'ils gagnent même moins qu'avant. Cela n'est pas démontré du tout. Le cléricalisme a fait, incontestablement, de grands progrès depuis l'Armistice. Les œuvres catholiques sont florissantes : nos adversaires eux-mêmes le proclament sur tous les tons.

Quant aux capitalistes, ils ont été ruinés pour la plupart (?) et par conséquent ils n'avaient pas le moindre intérêt à provoquer une guerre...

Mais alors, quels sont les responsables pour la sainte Croix?

Ne cherchez pas! C'est tout simplement le... peuple qui veut des guerres!!

La Croix compare la situation en 1914 avec celle de la Grèce antique : «C'est la populace qui règne; c'est elle qui veut la guerre; c'est elle qui mène Athènes à la catastrophe... »

En 1870 , ce n'était pas la bourgeoisie, ajoute notre auteur, qui criait : « À Berlin! » dans les rues de Paris. C'était la foule...

Mais cette foule, qui est-ce qui lui avait « bourré le crâne »? Sinon les journalistes, les gouvernants — les gens d'Église ! 
Affirmer que ce sont les pauvres qui provoquent les guerres, dire que les dirigeants, qui ont en mains tous les leviers de commande, sont obligés d'obéir aux populaces belliqueuses, c'est tout simplement de la démence.

Et cela nous prouve, une fois de plus, que l'Église est terriblement embarrassée pour esquiver la lourde responsabilité qui lui incombe. 


\section{XVI \\ LE PROBLÈME DE POPULATION ET L'ÉGLISE}

$\underline{\text { Retour à la table des matières }}$

Je n'ai pas la prétention, dans un ouvrage de propagande comme celui-ci d'avoir épuisé le sujet. Je n'ignore pas que mon exposé comporte des lacunes, mais il en est une que je tiens à signaler au lecteur. Je veux parler du problème de population.

En effet, il n'est pas douteux que la surpopulation engendre la misère et le chômage et que les nations trop peuplées constituent une menace permanente pour la paix (l'Allemagne en 1914, l'Italie et le Japon aujourd'hui etc., etc.) ${ }^{28}$.

28 La Croix du Périgord envoie ses félicitations chaleureuses au Gouvernement japonais (5-12-31).

Ce gouvernement a décidé, en effet, d'accentuer le caractère religieux de l'enseignement scolaire — et cela, dans le but de barrer la route au Communisme!!

La Croix jubile, mais elle oublie que ce gouvernement si moral (sic) et si religieux (resic) vient de donner un triste exemple au point de vue international. Le Japon n'a pas hésité à violer les traités et les pactes qui le liaient à un dizaine de puissances ; il a foulé aux pieds le droit international pour assouvir ses vieilles ambitions et s'emparer de la Mandchourie. 
La paix ne sera durablement établie : $1^{\circ}$ que dans un monde complètement transformé, où le travail sera roi (et non plus le Sabre et le Goupillon !) ; $2^{\circ}$ que lorsque le problème de la population aura été résolu par une entente internationale.

Il faut enseigner aux hommes qu'ils n'ont pas le droit de créer plus d'enfants qu'ils ne peuvent en élever raisonnablement. Il faut leur dire que c'est un crime que d'imposer la vie à de futurs malheureux - ou à des malades, à des souffreteux. Les lois de la sélection humaine consciente doivent être étudiées et répandues, ainsi que les moyens rationnels permettant à la femme d'être mère à son gré.

Mais ces doctrines sont prohibées et leurs propagandistes traqués (l'auteur de ce livre en a fait l'expérience !). Sous l'influence des clé-

Mais qu'importe à nos faux pacifistes chrétiens ! Les gouvernants peuvent être les derniers des brigands ; on les soutiendra et on les bénira quand même, à la seule condition qu'ils acceptent de protéger les religions.

Le très remuant chanoine LARIGALDY approuve également l'impérialisme japonais. Il va jusqu'à reprocher à la France d'avoir été trop pacifiste en 1914 et il se moque de la Société des Nations. Je cite :

« Peut-on blâmer le Japon? - Non, assurément, car le Japon a fait ce que feraient demain, dans des circonstances analogues, l'Angleterre, l'Allemagne, l'Italie et les États-Unis. Seule, peut-être, la France ne le ferait pas, en raison de cette mystique de la paix qui lui fit, en 1914, ouvrir les frontières aux Allemands par le fameux recul de 10 kilomètres. Ce serait pour son malheur.

«La S.D.N. a montré jusqu'à l'évidence son incapacité ? de régler de tels conflits. Elle n'a rien des déclarations et des votes pour la défense des droits : c'est insuffisant.

«Elle restera un parlement de la paix où les hommes d'État de tous les points du monde viendront discourir jusqu'à l'heure des coups de canon. Alors... » (« La Croix de la Charente », $1^{\mathrm{er}}$ novembre 1931).

Il paraît que les missionnaires sont assez souvent bousculés par les Chinois... Cela suffit pour que les catholiques manigancent l'écrasement de la Chine et fassent des vœux en faveur du Japon.

Pendant ce temps, les républicains français (libres penseurs, socialistes et même radicaux) demandent à leur gouvernement de consentir à l'annulation complète de la dette allemande, ce qui serait le meilleur moyen d'abattre Hitler et d'assurer la paix.

De quel côté sont les vrais pacifistes, du côté de l'Église ou du côté des laïques ? 
ricaux, une loi a été votée en France, interdisant toute propagande malthusienne.

Voilà donc encore un fait qui montre que l'Église ne veut pas œuvrer pour la paix d'une façon sérieuse.

La surpopulation, c'est la guerre.

Or l'Église est le plus chaud partisan de la surpopulation (à laquelle ses chastes représentants se gardent bien d'ailleurs de participer, tout au moins officiellement...)

L'Église a besoin de miséreux. Elle ne règne que par la maladie, la dégénérescence, la souffrance. Il lui faut de la chair à patronages, de la chair à pèlerinages, comme il faut au Capitalisme de la chair à travail et au Militarisme de la chair à canon...

Travailleurs, méfiez-vous donc de l'Église, toujours fourbe et hypocrite. Rompez avec elle définitivement, si vous désirez vraiment arriver à la Liberté et la Paix. 


\section{XVII}

\section{LEUR "PATRIOTISME”}

Les cléricaux revendiquent volontiers le monopole du patriotisme, assez difficile à concilier d'ailleurs avec le mépris que Jésus professait pour le métier des armes et les biens de ce monde.

Derrière cette façade tricolore, La Lumière montre, par la publication d'un document très suggestif, que les gens d'Église ne perdent jamais l'occasion de travailler pour leurs privilèges, avant toute autre chose.

C'était à Lille, en 1916, pendant l'occupation allemande par conséquent. M. MARGERIN, recteur de la Faculté catholique, publiait la prière ci-dessous, avec l'autorisation de la Censure allemande (et pour cause !).

«O notre père des Cieux, sous le poids des souffrances qui nous accablent, nous sentons le besoin de vous redire ce cri filial : «Je crois en votre amour pour moi. Et nous baisons votre main paternelle qui nous éprouve. 
« Vous nous frappez par amour, pour nous aider à expier nos péchés dès ce monde, par des souffrances fécondes et sanctifiantes, plutôt que dans les flammes terribles du Purgatoire. "Fiat et Merci ! »

« Vous nous frappez encore en expiation des péchés de notre Patrie bien-aimée, péchés des législateurs, qui, par une folie criminelle ont renié votre nom, persécuté votre Église, spolié nos religieux, élevé les enfants dans l'athéisme, péchés des électeurs qui, en votant pour des hommes sans religion, sont devenus leurs complices, responsables des lois impies de leurs mandataires et ont attiré sur le pays d'effroyables châtiments, péchés des égoïstes qui n'ont pas cherché à user de leur influence pour aider leurs frères à connaître et à remplir leur devoir !»"

«O mon Dieu, faites comprendre à tous nos concitoyens ce qui pèse sur leur conscience, ce bulletin de vote si léger en leur main, et qui entraîne pour le salut éternel et pour toute la nation de si terribles conséquences. »

«Convertissez-nous! Convertissez la France et rendez-lui sa foi antique, la gloire et la prospérité d'autrefois. Amen !»

« Notre Dame de la Treille,

« Priez pour nous. 40 jours d'indulgences.

«Vu et permis d'imprimer le 3 juillet 1916.

«A. MARGERIN, vicaire général, recteur de l’Université Catholique à Lille.

«Imprimerie de la Croix du Nord - Censure allemande ${ }^{\circ} 447$. »

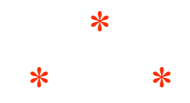

Si les hommes d'avant-garde, placés dans les mêmes conditions, avaient déblatéré contre la République de POINCARÉ, on les aurait traduits en Conseil de guerre ! 
Ce qui est particulièrement piquant dans le document qu'on vient de lire, c'est que ces attaques contre la France républicaine étaient faites pendant la guerre, en pays occupé, sous le regard amusé et satisfait de l'Allemand.

Peu importait aux cléricaux de faire du tort à leur pays ! Ils cherchaient avant tout à satisfaire leur animosité contre l'esprit laïque et libre penseur...

Tous les moyens sont bons aux Jésuites et ils profitent de toutes les circonstances pour arriver à leurs fins.

Mais... puisque leur vraie patrie est à Rome, pourquoi condamnent-ils l'internationalisme des ouvriers et des pacifistes?

Les gens d'Église sont vraiment peu qualifiés pour nous donner des leçons de patriotisme!

En 1914, ils ont déchaîné la guerre, pour punir la France et ramener la foi.

En 1925, pour abattre le gouvernement du Cartel des gauches, ils ont fait tomber le franc à dix centimes...

Que la France soit ruinée, peu leur importe. Ce qu'ils veulent, c'est l'asservir, la mettre à genoux. 


\section{XVIII \\ QUI FERA LA PAIX?}

$\underline{\text { Retour à la table des matières }}$

C'est encore La Croix, organe central des catholiques français, qui pose la question.

La paix se fera-t-elle par les gauches ou par les catholiques?

Dix-neuf siècles de Christianisme massacreur et sanglant pourraient nous dispenser de répondre à la question.

Il serait grand temps que l'Église montrât son pouvoir pacificateur car, à travers les siècles, elle a plutôt montré... le contraire !

L'article est de François VeuiLLot et j'y découpe l'aveu suivant :

«Car, il faut bien l'avouer, M. HerRIot, lorsqu'il accuse les catholiques de se montrer foncièrement hostiles aux réconciliations entre peuples et à la politique de paix, ne manque pas d'un certain prétexte. Ils sont encore trop nombreux chez nous, les catholiques affirmés et pratiquants, sinon actifs, éclairés et réfléchis, qui, formés ou plutôt déformés par des influences au moins contestables, affichent passionnément et systématique- 
ment contre toutes les tentatives pacifiques et toutes les rencontres internationales une méfiance aveugle, une ironie stérile, une opposition instinctive et irraisonnée. » - (23-9-1930)

M. VeuiLlot reconnait formellement que la plupart des catholiques sont pour la guerre (à commencer par son ancêtre dont nous avons reproduit les sanglantes théories).

Nous ne l'ignorons pas, car nous les voyons à l'œuvre depuis longtemps.

Les « revanchards », les « nationalistes », les « antisémites », les « jusqu'auboutistes », ceux qui nous traitaient de « défaitistes » ou de « vendus à l'Allemagne », tous ce gens-là étaient des cléricaux ou amis de l'Église.

Dans le camp opposé, nous trouvons au contraire les dreyfusards, les républicains convaincus, les socialistes, les pacifistes, les francsmaçons, les radicaux, les libres penseurs, les communistes, anarchistes, syndicalistes ; bref, tous les hommes d'avant-garde. Ce sont ceuxlà qui travaillent pour la paix, en abattant la puissance du Capitalisme et la tyrannie morale et politique de l'Église.

L'abandon de la lutte anticléricale a été un grand malheur, car il a permis aux Jésuites de manœuvrer à leur guise. Le résultat, nous le connaissons : 1'Église est fortifiée... dans une France ruinée et saignée aux quatre veines!

Pour éviter de futures guerres, pour assurer la Démocratie, pour assurer l'avenir social, réduisons l'Église à l'impuissance, barrons la route à ses Congrégations abrutisseuses et exploiteuses, serrons les rangs au service de la raison, de la justice sociale et de la paix internationale!

André LORULOT 


\section{Appendice}

\section{UNE PAGE D'HISTOIRE}

Mon regretté ami G. CATOIS, président de la Libre Pensée du Mans, avait publié (en 1910) une intéressante étude sur Le Patriotisme des gens d'Église. J'en extrais le suivant passage :

\section{«Ouvrons l’Histoire de France:}

«Au début de notre histoire alors que l'empire romain succombe, le Clergé des Gaules aurait pu au moins s'efforcer de sauver la civilisation toute faite dont nos ancêtres avaient hérité de Rome ; mais non, les rois établis en Gaule se refusaient à être les serviteurs de l'Église. Les évêques n'hésitèrent pas à livrer le sol gaulois aux envahisseurs barbares. Ils appelèrent CLOVIS, intriguèrent en sa faveur. Clovis consentit à être un instrument entre les mains du Clergé, à faire les affaires de l'Église; l'Église fit les siennes. «Partout où tu combats nous sommes victorieux », lui écrit l'évêque AviTus. Tout le pacte entre les évêques et Clovis se résume en peu de mots : "Conquiers, tue massacre et pille et nous partagerons. " 
«Pendant la Guerre de Cent Ans, le Clergé de France se tient dans l'expectative; il ne lui vient pas un instant à la pensée de profiter de l'influence, du crédit qu'il a sur les populations pour les entraîner contre les envahisseurs. Après la signature du traité de Troyes, le Clergé de France juge que l'Anglais doit l'emporter, que toutes les chances sont pour lui. Presque partout il se tourne vers l'envahisseur et le favorise. Dans notre contrée, le moine JOLIVET essaye de livrer le Mont Saint-Michel ; le chapelain du duc d'Alençon le pousse à se jeter dans le parti anglais; les chanoines du Mans tentent d'introduire les Anglais dans la ville. À la fin du règne de CHARLES VI, alors que le roi anglais débarquait en France pour dépouiller le dauphin, l'héritier légitime, le prince français, le clergé bat des mains, entonne des Te Deum en l'honneur de l'étranger.

«C'est que notre clergé, si peu national, si peu patriote, voyait déjà dans le roi anglais un puissant protecteur. Que faisaient alors à ce clergé des débâcles comme celle d'Azincourt ? HENRI V d'Angleterre se donnait comme un ami du clergé ; n'était-il pas réputé alors le roi des curés?

« Le chef de l'Église, le pape, prenait part à la lutte des deux peuples. « Des bulles du pape invitaient les gens d’Église de Normandie à donner au roi anglais deux dixièmes ou des sommes équivalentes pour les employer à la défense du pays. L'évêque de Beauvais Pierre CAUCHON, conseiller du roi d'Angleterre, "juge accompli en cette partie », désigna en chaque diocèse des commissaires et des receveurs, pour imposer et asseoir, lever, cueillir et recevoir le produit des dixièmes qui fut employé à payer les gens d'armes et de trait au service du roi anglais. » Quelle rapacité ne durent pas apporter dans la rentrée de ces dixièmes, ces prêtres français, devenus anglais de cœur, alors qu'ils croyaient trouver un avantage à favoriser l'étranger, l'ennemi de leur patrie !

« À ce moment même où la France ne va plus devenir qu'une possession anglaise, le patriotisme s'incarne dans une jeune fille, une pâtoure. Elle fascine le peuple, l'entraîne au secours de la France, accomplit des prodiges. Mais Jeanne d'ARC, trahie par la noblesse, par le roi, et livrée à l'Église. Les Louis de LuXEMBOurG, les Jean de Mailly, les Philibert de Montueu, les Pasquier de Vaux, les Thomas 
de Courcelles, et autres CAUChOn, de «bonne mémoire », ne lui pardonnent pas d'avoir détruit leurs espérances ; après avoir essayé de salir la noble et courageuse jeune fille, ils la brûlent pour gagner les faveurs de l'étranger, ne pensant pas qu'un jour leurs successeurs monnayeraient sa mémoire.

«Ah! leur audace est grande à eux, membres du Clergé actuel, successeurs des bourreaux de Jeanne d'Arc, quand ils veulent s'emparer de cette sainte mémoire, patrimoine commun de tous les Français !

«Pendant les guerres de religion, le Clergé Français fait cause commune avec l'étranger. Le vrai chef de la Ligue est l'ambassadeur espagnol qui tient à sa solde les agitateurs parisiens, les prédicateurs, les Roses, les Boucher, les Aubry, les FeuArdent, les GuÉnéBRARD, le manceau PORTAISE, toute le meute hurlante des clubistes d'église. Que la France fût avilie, qu'elle fût démembrée par le Lorrain, qui voulait prendre la Champagne ; par le Savoyard, qui voulait prendre le Dauphiné ; par l'Espagnol, qui voulait s'emparer de tout et qui, en attendant, prenait de gages en Languedoc, en Provence, en Bretagne, il importait peu à ces fanatiques, à ces vendus. Ils méritèrent le nom de parti de l'étranger, que MiCHELET leur inflige comme une flétrissure.

«Quant à la papauté, elle versait consciencieusement l'huile sur le feu.

«Le clergé français a donné la mesure de son patriotisme pendant les guerres de la Révolution. Quand nos jeunes armées tenaient tête héroïquement aux troupes de l'Europe coalisée, Mgr de la RoYĖRE, évêque de Castres, prescrivait un neuvaine par mois pour obtenir la défaite des armées françaises. Un autre évêque faisait fabriquer de faux assignats pour affaiblir sa patrie, pour ruiner le crédit de la France.

«Le patriotisme des membres du Clergé se limitait aux intérêts de leur caste. Entre une armée française combattant pour la République et une armée étrangère au service d'une Monarchie, leurs vœux al- 
laient à l'armée étrangère. Dans le Maine, les prêtres réfractaires « tisonnaient la guerre civile», selon l'expression de l'expression de l'abbé GRÉGOIRE. «Ils se chargent de propager les mauvaises nouvelles, de fanatiser les campagnes, d'y absoudre les assassins encore teints du sang de leurs victimes ", disent les administrateurs de la Sarthe et de la Mayenne.

«Par trois fois, en 1870, avant la funeste guerre avec l'Allemagne, l'Italie offrit à la France le salut si cette dernière voulait renoncer à défendre le pouvoir temporel du pape. Les cléricaux français avaient à choisir entre la France et Rome, entre les intérêts de la nation et ceux du pape : ils sacrifièrent au pape et repoussèrent la main tendue de l'Italie.

«La France était vaincue et le Clergé de France était en grande partie responsable de nos désastres, de nos ruines, des vies humaines sacrifiées, des cinq milliards payés à l'Allemagne, de la perte de nos provinces.

« À ce moment, est-ce que le patriotisme du Clergé était personnifié en ce cardinal de BONNECHOSE, archevêque de Rouen, qui, alors que la France est envahie par les hordes teutonnes et agonise sous les désastres successifs, ne songe qu'à protester « contre l'invasion » des États pontificaux par les troupes italiennes » et ne daigne s'occuper des souffrances de sa patrie que pour déclarer en un sermon du 28 octobre 1870, qu'elles sont un châtiment divin s'abattant sur un pays déchu?

«Le patriotisme du Clergé était-il davantage personnifié dans l'évêque DuPANLOUP, déclarant après son entrevue, à Ferrières, avec le prince prussien, que les exigences des Allemands n'avaient rien d'excessif, s'ils consentaient à rétablir dans la personne du comte de Chambord, la dynastie légitime?

«Le patriotisme du Clergé était-il personnifié dans les membres de cette association dite Propagation de la Foi ? En cette année 1871, alors que la France était couverte de sang et de ruines et faisait de suprêmes efforts pour trouver l'argent de sa rançon et hâter la libération 
de son territoire, ladite association ramassait plus de cinq millions de francs qu'elle envoyait à l'étranger et notamment en Allemagne...

«Le patriotisme n'est pas davantage personnifié dans ce parti clérical, à qui toute pensée patriotique fut de tout étrangère, qui multiplia tellement les manifestations pour précipiter la France dans une nouvelle aventure contre l'Italie, qualifiée de spoliatrice, qu'il finit pas jeter l'Italie malgré elle dans les bras de l'Allemagne, pour faire se conclure contre nous la Triplice de haine qui jusqu'à ces derniers temps a été une menace permanente, un danger de toutes les heures. »

Ce que dit Catols au sujet de l'Italie est confirmé par tous les écrivains impartiaux.

Ainsi, M. Albert Letellier, avocat à la Cour d'appel de Paris, écrit 29 :

«Le général FLEURY partit en mission en Italie avec une note de l'empereur (NAPOLÉON III) qui contenait, en outre, ces instruction : «L'empereur, par conviction autant que par intérêt politique, ne peut pas abandonner le Saint-Père et emploiera tous ses efforts pour l'empêcher de quitter Rome.

« Si donc, après le départ des troupes françaises, le pape était obligé de se retirer devant une émeute, l'empereur n'hésiterait pas à le ramener avec ses troupes. Dans ce but, il laissera toujours, entre Toulon et Marseille, 20000 hommes prêts à être transportés à CivitaVecchia, au premier appel. [Ceci se passait en 1867.]

« Vous connaissez la suite : La perte de la Lorraine et de l'Alsace, tandis que, si nous avions été secondés par VICTOR-EMMANUEL II et son royaume, GUILlAUME ${ }^{\text {er }}$ et BISMARCK eussent été, peut-être, en trois mois, amenés enchaînés à Paris.

29 La politique du Vatican et la France. 
« Et puis, qu'aurait fait alors l'Autriche ? Et la Russie, qui inspirait à Bismarck, du matin au soir, tout le temps de la guerre, une sainte terreur?

« Des offres furent, au reste, constamment portées à NAPOLÉON III, avant qu'il ne fut fait prisonnier, et, toujours, il les repoussa.

« On objectera que, personnellement, l'empereur n'était pas fanatique. Il n'empêche que ceux qui lui dictèrent sa politique l'étaient. »

Les républicains, en particulier COMBES, DELCASSÉ, LOUBET, réparèrent trente ans plus tard les erreurs de la politique impériale, en ce qui concerne l'Italie. Lorsque le président se rendit à Rome, il alla au Quirinal voir le Roi, mais refusa d'aller au Vatican. La rupture entre le Vatican et la République française en résulta, mais par contre l'Italie se détacha de la Triple-Alliance et refusa en 1914 de marcher avec l'Allemagne.

L'écrasement de la France en 1870 fut donc incontestablement la conséquence de la politique cléricale adoptée par EUGÉNIE de MONTIJo. et la guerre de 1914 en découle...

Qu'importe aux gens d'Église ! À travers les deuils et les ruines ils fortifient leur malsaine et redoutable tyrannie.

Le présent ouvrage était imprimé lorsque notre éminent ami Victor MARGUERITTE a publié son livre sur Aristide BRIAND.

Avec son grand talent et son habituel courage, le maître écrivain écrit (p. 136, 137), au sujet de POINCARÉ :

«La guerre! Qu'une telle hantise fut celle du président lorrain, je n'en veux, s'ajoutant à tous les témoignages historiques, que cette preuve: les mots prononcés CHEZ MOI, en 1912, par Mme POINCARÉ, peu après l'avènement de son mari à la présidence du Conseil. Regrettant l'occasion d'Agadir passée, elle déclara, je l'entends en- 
core : " CE QU'IL FAUDRAIT, C'EST UNE BONNE GUERRE ET LA SUPPRESSION DE JAURÈS. " Propos si familiers dans sa bouche qu'un an plus tard, recevant à l'Élysée, elle les réitéra devant plusieurs personnes... »

Ces odieuses paroles, prononcées par la femme de POINCARÉ-laGuerre, viennent à point confirmer toute la thèse soutenue dans ce modeste ouvrage.

Conclusion : Si vous voulez la paix, balayez la réaction et écrasez le Cléricalisme !
A. L.

Fin du texte 